\title{
The inhibition of assembly of HIV-I virus-like particles by 3-O-(3', 3'-dimethylsuccinyl) betulinic acid (DSB) is counteracted by Vif and requires its Zinc-binding domain
}

\author{
Sandrina DaFonseca ${ }^{1}$, Pascale Coric ${ }^{2}$, Bernard Gay ${ }^{3,4}$, Saw See Hong1, \\ Serge Bouaziz ${ }^{2}$ and Pierre Boulanger*1,3,4
}

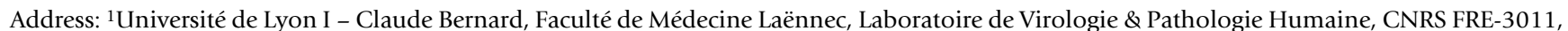
69372 Lyon Cedex 08, France, 2Université de Paris VII - René Descartes, UFR des Sciences Pharmaceutiques et Biologiques, Unité de Pharmacologie Chimique et Génétique, INSERM U-640 and CNRS UMR-8151, 75006 Paris, France, ${ }^{3}$ Universités de Montpellier I et II, Centre d'Etudes d'Agents Pathogènes et Biotechnologies pour la santé, CNRS UMR-5236, Institut de Biologie, 4, Boulevard Henri IV, 34965 Montpellier Cedex 02, France and ${ }^{4}$ Laboratoire de Virologie Médicale, Centre de Biologie et Pathologie Est, Hospices Civils de Lyon, 59, Boulevard Pinel, 69677 Bron Cedex, France

Email: Sandrina DaFonseca - sandrinedafonseca@hotmail.com; Pascale Coric - pascale.coric@univ-paris5.fr; Bernard Gay - bernard.gay@univmontp1.fr; Saw See Hong - sawsee.hong@sante.univ-lyon1.fr; Serge Bouaziz - serge.bouaziz@univ-paris5.fr;

Pierre Boulanger* - serge.bouaziz@univ-paris5.fr

* Corresponding author

Published: 23 December 2008

Virology Journal 2008, 5:162 doi:10.1186/1743-422X-5-162

This article is available from: http://www.virologyj.com/content/5/I//62

This is an Open Access article distributed under the terms of the Creative Commons Attribution License (http://creativecommons.org/licenses/by/2.0), which permits unrestricted use, distribution, and reproduction in any medium, provided the original work is properly cited.

\begin{abstract}
Background: DSB, the 3-O-(3',3'dimethylsuccinyl) derivative of betulinic acid, blocks the last step of protease-mediated processing of HIV-I Gag precursor (Pr55Gag), which leads to immature, noninfectious virions. When administered to Pr55Gag-expressing insect cells (Sf9), DSB inhibits the assembly and budding of membrane-enveloped virus-like particles (VLP). In order to explore the possibility that viral factors could modulate the susceptibility to DSB of the VLP assembly process, several viral proteins were coexpressed individually with Pr55Gag in DSB-treated cells, and VLP yields assayed in the extracellular medium.

Results: Wild-type Vif (Vifwt) restored the VLP production in DSB-treated cells to levels observed in control, untreated cells. DSB-counteracting effect was also observed with Vif mutants defective in encapsidation into VLP, suggesting that packaging and anti-DSB effect were separate functions in Vif. The anti-DSB effect was abolished for VifCI33S and VifSII6V, two mutants which lacked the zinc binding domain (ZBD) formed by the four $\mathrm{H}^{108} \mathrm{Cl}^{114} \mathrm{C}^{133} \mathrm{H}^{139}$ coordinates with a $\mathrm{Zn}$ atom. Electron microscopic analysis of cells coexpressing Pr55Gag and Vifwt showed that a large proportion of VLP budded into cytoplasmic vesicles and were released from Sf9 cells by exocytosis. However, in the presence of mutant VifC I33S or VifSI I6V, most of the VLP assembled and budded at the plasma membrane, as in control cells expressing Pr55Gag alone.

Conclusion: The function of HIV-I Vif protein which negated the DSB inhibition of VLP assembly was independent of its packaging capability, but depended on the integrity of ZBD. In the presence of Vifwt, but not with ZBD mutants VifCI33S and VifSII6V, VLP were redirected to a vesicular compartment and egressed via the exocytic pathway.
\end{abstract}




\section{Introduction}

The 3-O-(3',3'-dimethylsuccinyl)-betulinic acid (or YKFH312 [1], or PA-457 [2], or Bevirimat $\left.{ }^{\mathrm{TM}}[3,4]\right)$, has been used as an antiviral which blocks HIV-1 replication via its inhibitory activity on Gag polyprotein maturation [2,5-8]. DSB differs from conventional protease (PR) inhibitors in that it does not bind to PR, but interferes with the PRmediated Gag processing. The ultimate cleavage of the $\mathrm{C}-$ terminal capsid domain CAp25 into CAp24 + SP1 is required for production of fully infectious virions [9]. DSB blocks this step, and decreases or abolishes virus infectivity $[2,4,6,10]$. Several lines of evidence indicate that the CA-SP1 junction is the preferred target of DSB in HIV-1 Gag precursor $[3,4,8,11]$. Although there is no available structural data on DSB-Gag complex which could explain its inhibitory activity at the molecular level, data from in vitro experiments [12], as well as the encapsidation of DSB in equimolar ratio to Gag in vivo [13], suggested that the mechanism of inhibitory activity of DSB results from the direct binding of DSB to the Gag polyprotein, or/and to a transient Gag structural intermediate which occurs during virus assembly.

The latter observation incited us to study the possible effect of DSB on assembly of recombinant HIV-1 Gag precursor (Pr55Gag) expressed in heterologous, eukaryotic system. We observed a dose-dependent negative effect of DSB on the process of assembly and release of HIV-1 VLP from recombinant baculovirus AcMNPV-Pr55Gaginfected cells [14]. This effect was not due to a block in Gag synthesis, and was independent of the N-myristoylation of Pr55Gag and its plasma membrane addressing. It did not depend on the presence of the p 6 domain at the C-terminus of Gag. The same effect was observed with the Gag precursor of SIVmac (Pr57GagSIV), although at significantly higher DSB concentrations, suggesting that the DSB inhibitory activity on Gag assembly was not as strictly sequence-dependent as the negative effect on Gag processing at the CA-SP1 junction [8]. In addition, we found a lower stability of delipidated cores assembled in the presence of DSB, compared to control cores, suggesting a weakening of Gag-Gag interaction occurring in the presence of DSB [14]. Using Gag mutants and a chimeric HIVMuLV Gag precursor, we mapped the DSB-responsive domain in terms of Gag assembly to the hinge region overlapping the C-terminal end of the CAp24 and the SP1 domain [14].

The DSB concentration at which we observed an inhibitory activity on Gag assembly in insect cells (IC50 8-10 $\mu \mathrm{M})$ was apparently disproportionate compared to the usual doses required for blocking the CAp25 cleavage in HIV-1-infected mammalian cells. However, a wide range of IC-50 values have been reported for the DSB inhibition of virus maturation, varying from nanomolar $(0.35 \mathrm{nM}$
[15] and $7.8 \mathrm{nM}$ [2]) to micromolar values (10 $\mu \mathrm{M}$ [12]), depending on the different assays used. In addition, in Pr55Gag-expressing Sf9 cells, the bulk of Gag protein molecules synthesized at $48 \mathrm{~h}$ pi has been evaluated to be as high as $5 \times 10^{8}$ per cell [16]. The addition of DSB at $10 \mu \mathrm{g} /$ $\mathrm{ml}$ to $10^{6}$ cells corresponded to $12 \times 10^{9} \mathrm{DSB}$ molecules per cell, i.e. a DSB to Gag stoichiometric ratio of 24: 1 at this DSB concentration. A 24-fold excess of DSB over Gag was therefore compatible with a mechanism of Gag assembly inhibition due to a stoichiometric interaction between the drug and its protein target.

Whatever the molecular mechanism, our observation raised the question of the difference between Pr55Gagexpressing Sf9 cells, in which DSB inhibited VLP assembly [14], versus HIV-1-infected human cells, in which DSB was found to block the CA-SP1 (CAp25) to CAp24 maturation cleavage $[3,4,8,11]$, and to have limited effects on virus assembly [1]. In our experimental model of baculovirus-infected cells [14], assembly of Pr55Gag was analyzed in a context devoid of PR and of glycoproteins (Gp) SUgp120 and TMgp41, three viral components which have been identified as directly or indirectly involved in the antiviral effects of betulinic acid derivatives $[8,17,18]$. In the aim to reconcile the different antiviral activities of DSB, we explored cellular and viral determinants of the DSB response, and their possible role in modulating the degree of susceptibility to DSB of the VLP assembly process. Among the viral candidates, we analyzed EnvGp160, the precursor to the envelope glycoproteins (reviewed in [19]), and two inner core components, the Vpr and Vif proteins. $\mathrm{Vpr}$ is packaged into the virion in substoichiometric amounts with Gag [20-23], and Vif, which is also coencapsidated with Gag, has been found to exert a control on proteolytic processing of Gag in insect cells [24] and human cells [25].

We found that coexpression of wild-type Vif protein (Vifwt) with Pr55Gag restored the VLP assembly in DSBtreated Sf9 cells at levels observed in the absence of the drug, suggesting an antagonistic effect of Vif towards DSB. Data obtained with Vif mutants indicated that the antiDSB function of Vif required the integrity of the zinc binding domain (ZBD) recently identified in the Vif protein [26-28], but was independent of the Vif packaging function. Electron microscopic analysis showed that coexpression of Pr55Gag and Vifwt, in the presence or absence of DSB, resulted in a major change in the VLP egress pathway: the majority of VLP budded in intracytoplasmic vesicles and were released by exocytosis, instead of budding at the plasma membrane as in cells expressing Pr55Gag alone. With ZBD mutants of Vif however, the VLP budding pathway was similar to that observed in cells expressing Pr55Gag alone. Our data suggested that the anti-DSB effect of Vif, a novel function associated with its ZBD, was 
the indirect consequence of its effect on the cellular pathway of VLP assembly and budding.

\section{Results}

\section{Antiviral effects of DSB and cellular context}

We first compared the effect of DSB on VLP assembly and release in our reference model of AcMNPV-Pr55Gaginfected Sf9 cells [14] and in a trans-packaging mammalian cell line. 5BD.1 cells derive from CMT3-COS cells by integration of a discontinuous HIV-1 progenome, and stably express the gag, gagpol, rev and env gene products but no Nef protein. 5BD. 1 cells also express Vif protein in significant amounts [29,30]. 5BD.1 and Sf9 cells represented a similar situation in terms of VLP content, as both cell types produced VLP devoid of viral genomic RNA. DSB was added to monolayers of 5BD.1 cells at increasing concentrations for $30 \mathrm{~h}$, and whole cell lysates and VLP recovered from culture medium were analyzed for Gag protein content at the end of this time period.

\section{(A) Sf9 cells}

(i) WCL

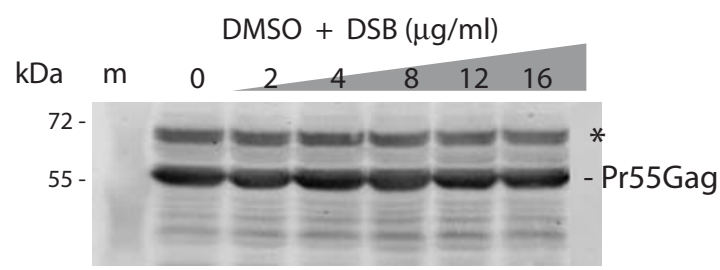

(ii) VLP

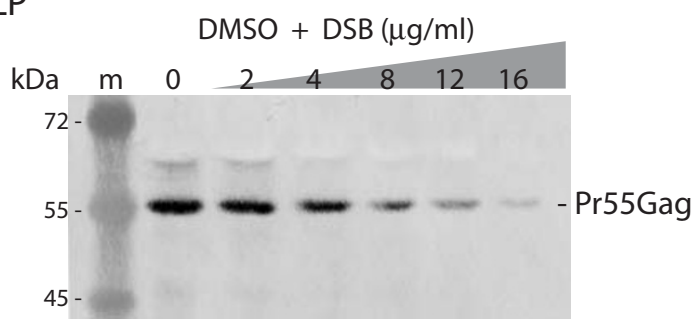

The intracellular Gag content was found to remain constant throughout the period of DSB treatment in both Sf9 and 5BD.1 cells (Fig. 1Ai and 1Bi), which confirmed that DSB had no significant effect on the level of Gag protein synthesis [14]. However, a drastic decrease in the yields of extracellular VLP was observed at DSB doses superior to 4 $\mu \mathrm{g} / \mathrm{ml}$ in Pr55Gag-expressing Sf9 cells (Fig. 1Aii; and refer to [14]). By contrast, only a moderate decrease in VLP production (20-30\%) was detected for DSB-treated 5BD.1 cells at high DSB concentrations (12 to $16 \mu \mathrm{g} / \mathrm{ml}$; Fig. 1Bii). Protein analysis of VLP showed that their Gag protein content mainly consisted of Pr55Gag and CAp24 proteins, with other minor species migrating at the expected position for intermediate cleavage products, e.g. Pr47 to Pr41 (Fig. 1Bii). Prolonged exposure of autoradiograms of immunoblots reacted with radiolabelled secondary antibody revealed a discrete alteration of the Gag processing at high DSB concentrations: there was a progressive increase in the amount of uncleaved CAp25 versus the

(B) 5BD. 1 cells

(i) $\mathrm{WCL}$

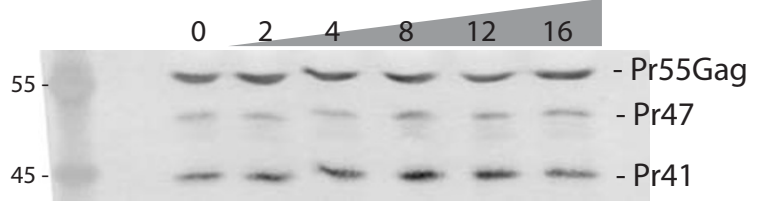

(ii) VLP

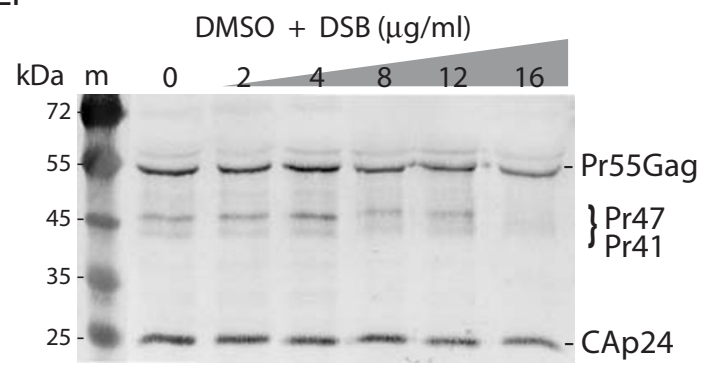

(iii) VLP

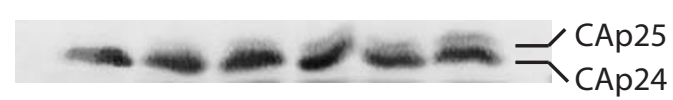

\section{Figure I}

Effects of DSB on HIV-I VLP production by (A) insect cells and (B) mammalian cells. (A), Sf9 cells infected with AcMNPV-Pr55Gag were treated with increasing concentrations of DSB in DMSO-aliquots for $30 \mathrm{~h}$ at $18 \mathrm{~h}$ pi, as indicated on top of the panels. Cells were harvested at $48 \mathrm{~h}$ pi, and whole cell lysates (WCL) and extracellular VLP recovered from the culture medium were analyzed by SDS-PAGE and immunoblotting using anti-Gag polyclonal antibody and phosphatase-labelled anti-rabbit IgG antibody. (i), WCL. (*), Asterisk marks posttranslationally modified Gag precursor (ubiquitinated and/or phosphorylated). This Gag species was not included in the quantification of Pr55Gag polyprotein. (ii), Extracellular VLP. (B), 5BD.I packaging cells were treated with increasing DSB concentrations in DMSO for $30 \mathrm{~h}$, as indicated on top of the panels, and cells and VLP collected separately and analyzed as above. (i), WCL; (ii), VLP. (iii), Same experiment as in (ii), except for the immunoblot analysis, which was performed using ${ }^{35}$ S-labelled secondary antibody. Shown in (iii) is an autoradiogram of the blot. Molecular markers $(\mathrm{m})$ were electrophoresed on the left side of the gels, and their molecular masses are indicated in kiloDaltons $(\mathrm{kDa})$. 
CAp24 species (Fig. 1Biii), as expected from previous studies $[3,4,8,11]$.

VLP assembly and release were therefore less sensitive to DSB inhibitor in 5BD.1 cells compared to Gag-expressing Sf9 cells. This suggested that the DSB sensitivity of the VLP assembly pathway might be modulated by the cellular context in which the HIV-1 Gag precursor was expressed, or/and by viral proteins present in 5BD.1 cells and absent from Sf9 cells. The following experiments were designed to address this issue, and to determine which factor(s) possibly interfered with DSB inhibitory activity and accounted for the difference in DSB response between Sf9 and 5BD.1 cells, as well as other mammalian cells.

\section{Absence of detectable effect of EnvGp/60 or Vpr on the DSB inhibition of VLP assembly in Sf9 cells}

The best candidates to act as viral modulators of the Gag assembly response to DSB were the HIV-1 proteins coencapsidated with Gag, in particular those which are active participants in the virus assembly pathway (reviewed in $[19,31])$. This was the case for the envelope glycoprotein Gp160, which has been shown to interact with the MA protein via the cytoplasmic tail of its TMgp41 domain [3236], as well as for auxiliary viral proteins Nef, Vpr and Vif.

In order to test this possibility, Sf9 were coinfected with AcMNPV-Pr55Gag and AcMNPV-Gp160, and subjected to increasing doses of DSB for $30 \mathrm{~h}$, at $18 \mathrm{~h}$ pi. Culture medium samples were collected at $48 \mathrm{~h}$ pi and assayed for production of extracellular VLP. Results were compared with VLP yields from Sf9 cells infected with AcMNPVPr55Gag alone and treated in parallel with DSB at the same doses. No significant difference in the DSB effect on VLP assembly was detectable with or without coexpression of EnvGp160 (data not shown). This excluded the direct or indirect participation of HIV-1 envelope glycoproteins in the level of susceptibility to DSB of assembly and extracellular release of VLP by Sf9 cells.

Nef in its processed form, called Nef core, has been shown to be a bona fide component of the virion inner core [3740]. In 5BD.1 cells, which do not express Nef but express Vif $[29,30]$, we observed a significantly lesser inhibitory effect of DSB on VLP assembly, compared to Gag-expressing Sf9 cells (refer to Fig. 1Bii). Considering that Nef protein was absent from both Sf9 and 5BD.1 cells, the difference in DSB response between these two cell types apparently excluded Nef as a possible modulator of the DSB sensitivity of VLP assembly.

Vpr is coencapsidated with Gag via interaction of the Nterminal alpha-helical domain encompassing residues 17-33 in Vpr [41-44] with the LXXLFG motif in the p6 domain of Gag [21,22,45-48]. In Sf9 coinfected with AcM-
NPV-Pr55Gag and AcMNPV-Vpr, the same DSB sensitivity of VLP assembly was observed as in cells solely expressing AcMNPV-Pr55Gag: both Pr55Gag and Vpr protein signals decreased in parallel and in DSB dose-dependent manner in the extracellular medium of DSB-treated cells, although their intracellular content remained unchanged (Fig. 2). This implied that Vpr did not significantly interfere with the inhibitory effect of DSB on Gag assembly.

\section{Antagonistic effect of Vifwt on the DSB inhibition of HIV-I VLP assembly}

HIV-1 Vif protein has been shown to interact with Pr55Gag in vitro and in vivo $[49,50]$, to control the viral PR-mediated processing of Gag in mammalian and insect cells $[24,25,51]$, and to be coencapsidated with Gag at a level of 70-100 copies of Vif protein per HIV-1 virion or VLP $[24,25,50,52-57]$. Sf9 cells coinfected with AcMNPVPr55Gag and AcMNPV-Vifwt showed a pattern of DSB effect different from that observed in cells expressing Pr55Gag alone: there was no significant decrease in the VLP yields from DSB-treated Sf9 cells, up to drug concentrations as high as $20 \mu \mathrm{g} / \mathrm{ml}$, implying that expression of Vif ${ }^{w t}$ protein negated the DSB inhibition of VLP assembly process in Pr55Gag-expressing insect cells (Fig. 3b, c). Of note, the Vif content of VLP progressively decreased in a DSB-dependent manner $(25-30 \%$ less than in control sample at $20 \mu \mathrm{g} / \mathrm{ml} \mathrm{DSB}$; Fig. 3b, c), although the intracellular content of Vif and Pr55Gag remained stable up to high DSB doses (16-20 $\mu \mathrm{g} / \mathrm{ml}$; Fig. 3a). This suggested a direct or indirect interference of Vif with DSB in virus assembly, resulting in the abrogation of the DSB negative effect on this process.

\section{Anti-DSB activity of packaging-defective mutants of Vif}

In a previous study, we have constructed and characterized Vif mutants which differed from Vifwt in their efficiency of copackaging with Pr55Gag into VLP produced by recombinant baculovirus-coinfected cells [50]. The two discrete regions involved in this function spanned residues 76-80 and 89-94, respectively (Fig. 4). Substitution mutants VifsubA ( ${ }^{76} \mathrm{EKEWH}^{80}$ to ${ }^{76} \mathrm{DINQN}^{80}$ ), VifsubB $\left({ }^{89} \mathrm{WR}^{90}-\mathrm{Y}^{94}\right.$ to $\left.{ }^{89} \mathrm{FE}^{90}-\mathrm{F}^{94}\right)$, double mutant VifsubC $(s u b \mathrm{~A}+s u b \mathrm{~B})$, and triple mutant VifsubC $\Delta 170$ carrying the double mutation subA+subB and a deletion of the C-terminal twenty-three residues, were found to be defective to various degrees in the encapsidation of Vif into VLP: Vif$s u b \mathrm{~A}, \mathrm{VifsubB}$ and VifsubC were partially defective in Vif packaging (40-50\% the levels of Vifwt), whereas this function was totally abolished in VifsubC $\Delta 170$ [50]. On the opposite, VifKRA8, a full-length Vif mutant which had eight basic residues in the C-terminal domain replaced by neutral alanine residues (Fig. 4) and lacked the plasma membrane addressing function [54], was packaged into VLP at levels higher than Vif ${ }^{\mathrm{wt}}$ [50], suggesting that plasma 
(A) Pr55Gag + Vpr : VLP

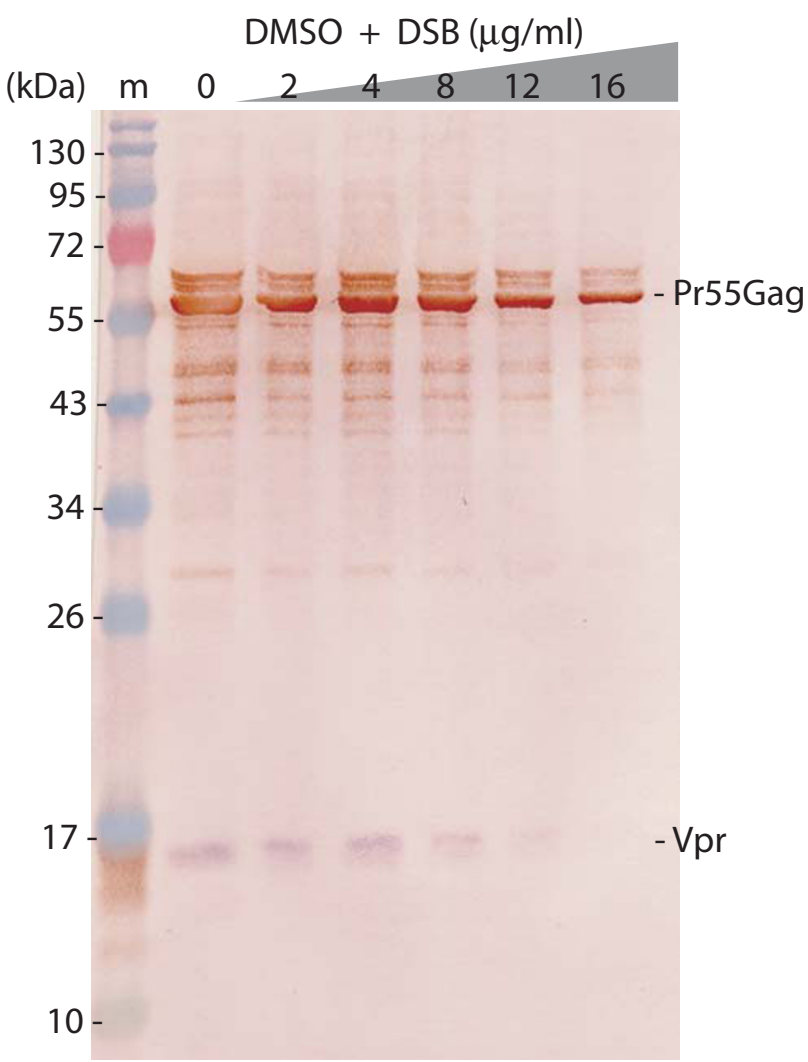

(B) Pr55Gag + Vpr : WCL

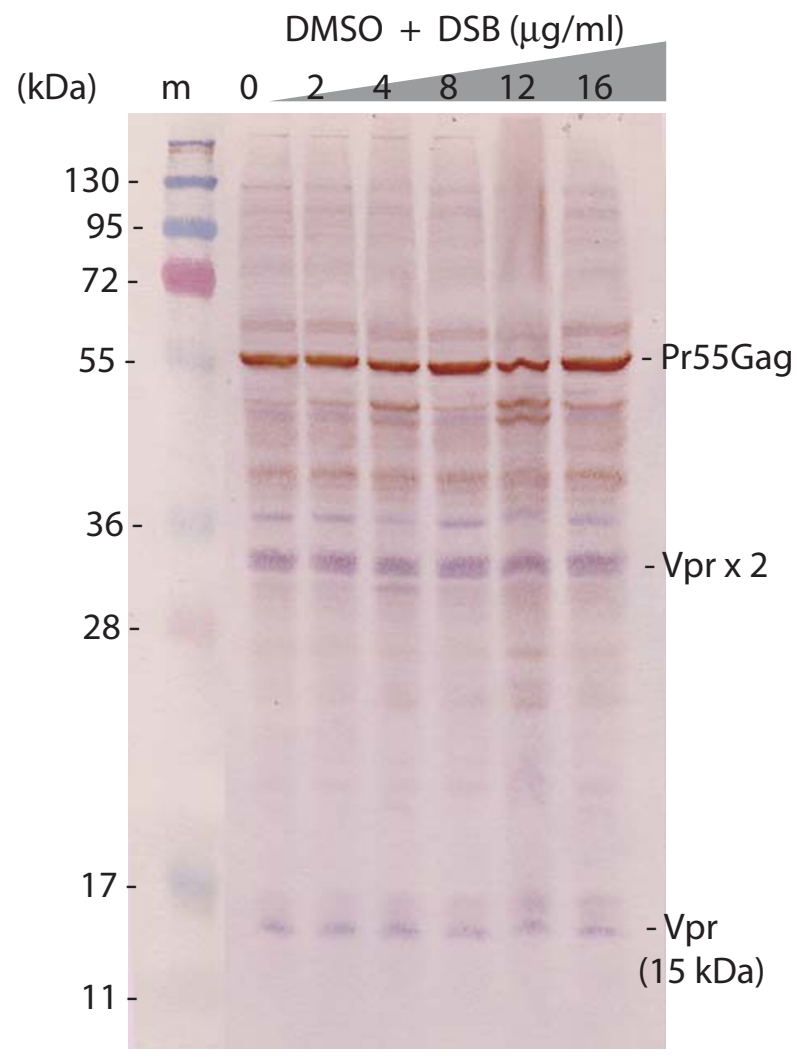

\section{Figure 2}

Absence of counteracting effect of Vpr on DSB inhibition of HIV-I VLP assembly and release. Sf9 cells were coinfected with two baculoviruses at equal MOI each (5 PFU/cell), one expressing Pr55Gag, the other expressing His-tagged Vpr. Cells were treated with increasing concentrations of DSB in DMSO aliquots for $30 \mathrm{~h}$ at $18 \mathrm{~h}$ pi, as indicated on top of the panels. Cells were harvested at $48 \mathrm{~h} \mathrm{pi}$, and whole cell lysates $(\mathrm{WCL})$ and extracellular VLP analyzed by SDS-PAGE and immunoblotting, using anti-His mAb and phosphatase-labelled anti-mouse IgG antibody, followed by anti-Gag rabbit antibody and peroxidase-labelled anti-rabbit IgG antibody. (A), VLP. (B), WCL. Note the occurrence of Vpr dimer (Vprx2; $30 \mathrm{kDa})$, stained in blue with the phosphatase reaction. $(\mathrm{m})$, prestained molecular mass markers; $(\mathrm{kDa})$, kiloDaltons.

membrane localization and encapsidation into VLP were distinct functions in Vif.

We then tested the anti-DSB activity of Vif mutants with different encapsidation phenotypes. With VifsubC, the production of extracellular VLP remained virtually unchanged throughout the DSB concentration range, with less than $15 \%$ decrease in VLP production at high DSB doses (Fig. 5). As observed with Vifwt (refer to Fig. 3b, c), there was a DSB-dependent, progressive decrease of VifsubC mutant protein content in VLP, relative to the Pr55Gag content, with 20-30\% lesser Vif protein incorporated at high DSB doses, compared to control samples (Fig. 5b, c, samples 16-20). A similar DSB resistance pattern as with Vifwt and VifsubC was observed with the other packaging-defective mutants VifsubA, VifsubB, and VifsubC $\Delta 170$ (not shown). Likewise, the packaging-effi- cient mutant VifKRA8 showed the same phenotype as Vifwt and the packaging-defecting mutants in terms of anti-DSB activity (not shown). These results suggested that the DSB-counteracting function of Vif was independent from the packaging function of Vif.

\section{Involvement of the zinc-binding domain of Vif in its anti- DSB function}

A conserved region of the Vif protein, within residues 108 to 140 , has been recently characterized as a non-canonical zinc-coordinating structure, generated by the $\mathrm{H}^{108}, \mathrm{C}^{114}$, $\mathrm{C}^{133}$ and $\mathrm{H}^{139}$ coordinates (HCCH) with a $\mathrm{Zn}$ atom $[27,28]$. This zinc-binding domain (ZBD) has been identified as the interacting region with the Cullin5 (Cul5) E3ubiquitin ligase [28]. It has been shown that Vif recruits cellular proteins ElonginB/ElonginC and Cul5 via its BCbox and ZBD domain, respectively, and the resulting E3- 
(a) WCL : HIV-1 Gag + Vif wt

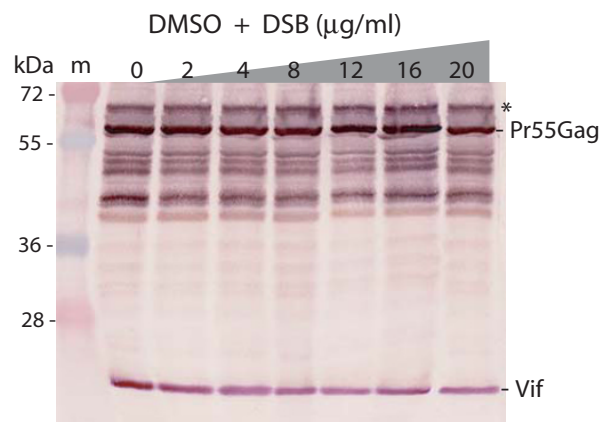

(b) VLP : Gag and Vif wt co-packaging

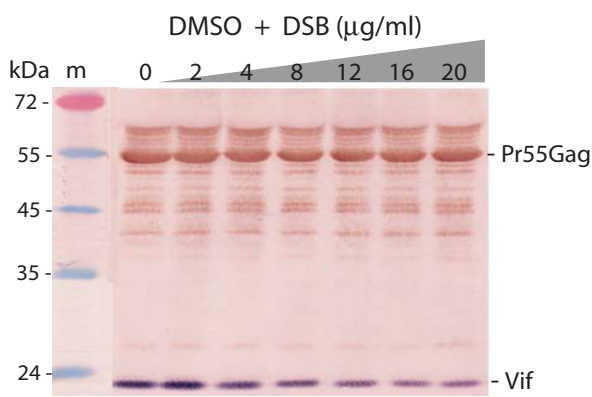

(c) Quantification of Gag and Vif wt

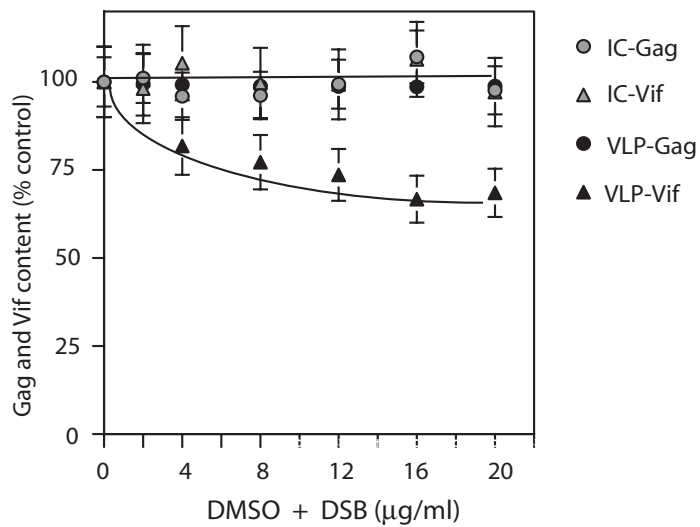

Figure 3

Influence of Vif on the DSB susceptibility of HIV-I VLP assembly in Sf9 cells. Sf9 cells were coinfected with equal $\mathrm{MOI}(5 \mathrm{PFU} / \mathrm{cell})$ of two baculoviruses expressing Pr55Gag and Vif, respectively. Cells were treated with increasing concentrations of DSB in DMSO for $30 \mathrm{~h}$ at $18 \mathrm{~h} \mathrm{pi}$, as indicated on top of panels (a) and (b), and the $x$-axis of panel (c). Cells were harvested at $48 \mathrm{~h}$ pi, and whole cell lysates (WCL) and extracellular VLP analyzed by SDS-PAGE and immunoblotting. Blots were reacted with anti-Vif primary antibody and secondary phosphatase-labelled antibody, followed by anti-Gag primary antibody and secondary peroxidase-labelled antibody. (a), WCL. (*), Asterisk marks posttranslationally modified Gag precursor (ubiquitinated and/or phosphorylated). This Gag species was not included in the quantification of Pr55Gag polyprotein. (b), VLP. Molecular mass of prestained markers $(\mathrm{m})$ are indicated in kiloDaltons (kDa) on the left side of panels (a) and (b). (c), Quantification of Gag and Vif proteins in WCL (IC-Gag, intracellular Gag; IC-Vif, intracellular Vif) and extracellular VLP, using SDSPAGE and radio-immunoblotting. Gag and Vif protein contents were quantified by autoradiography of immunoblots reacted with anti-Gag and anti-Vif rabbit primary antibodies and ${ }^{35} \mathrm{~S}$-labelled secondary anti-rabbit $\lg G$ antibody. After autoradiography of the blots, bands of Pr55Gag and Vif proteins were excised and their radioactive content determined by liquid scintillation spectrometry. Results were expressed as percentage of control, untreated samples, which was attributed the $100 \%$ value. Mean of three separate experiments \pm standard deviation. 
(A) Sequence alignment of recombinant Vif proteins, wt and mutants

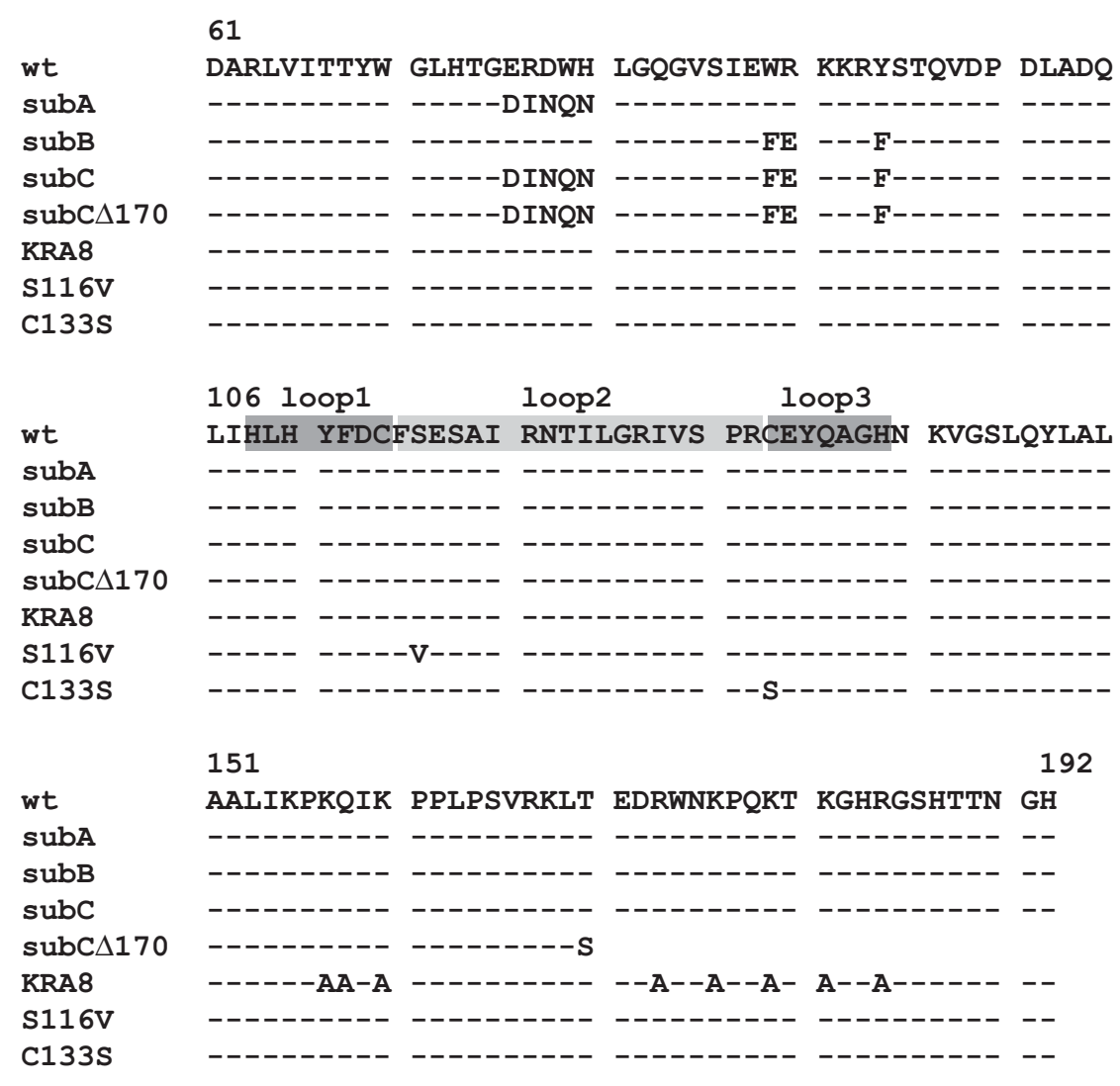

(B) Expression of recombinant Vif proteins in Sf9 cells

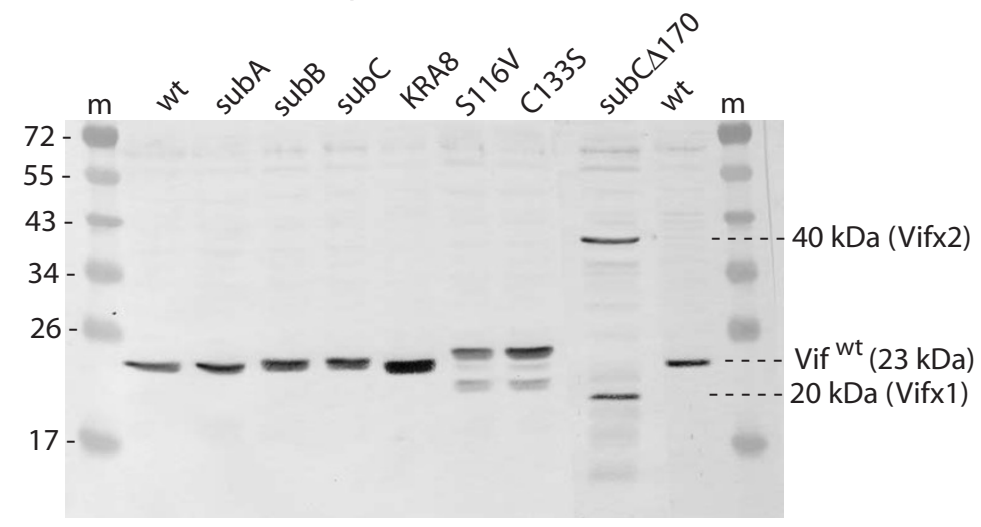

\section{Figure 4}

Genotype and expression of recombinant Vif mutants in Sf9 cells. (A), Sequence alignment of the central and C-terminal domains of HIV-I Vif proteins, WT and mutants. The zinc binding domain (ZBD) and its three constitutive loops are boxed: loops I and 3 are indicated as dark grey boxes, central loop 2 as a lighter grey box. (B), Cellular expression of recombinant Vif proteins, wild-type and mutants, in baculovirus-infected Sf9 cells. Sf9 cells were infected with baculoviruses (MOI 5) expressing different forms of Vif, as indicated on top of the panel, and harvested at $48 \mathrm{~h}$ pi. Whole cell lysates were analyzed by SDS-PAGE and immunoblotting, using anti-Vif primary antibody and secondary peroxidase-labelled antibody. The full-length ZBD mutants VifCI33S and VifI I6V show an aberrant electrophoretic mobility, as they migrate with a higher apparent molecular weight compared to Vifwt $(23 \mathrm{kDa})$, and a higher sensitivity to proteolysis, as evidenced by the discrete bands of lower molecular weight breakdown products. Note the propensity of the Vif protein of triple mutant VifsubC $\Delta \mathrm{I} 70(20 \mathrm{kDa})$ to dimerize (Vifx2; 40 kDa). 
(a) WCL : Pr55Gag +VifsubC

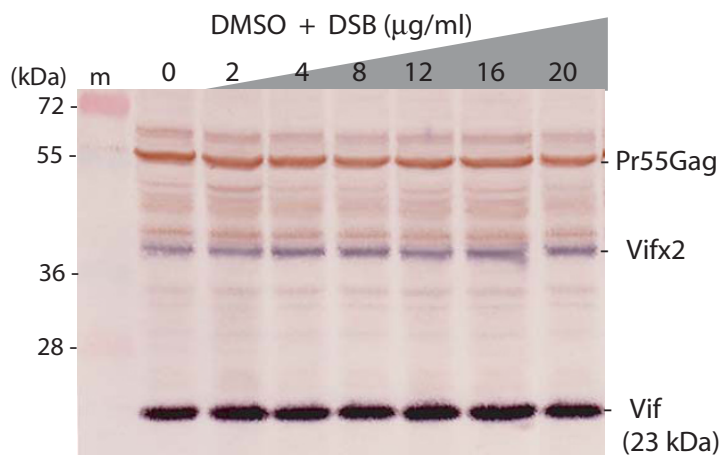

(b) VLP : Gag +VifsubC

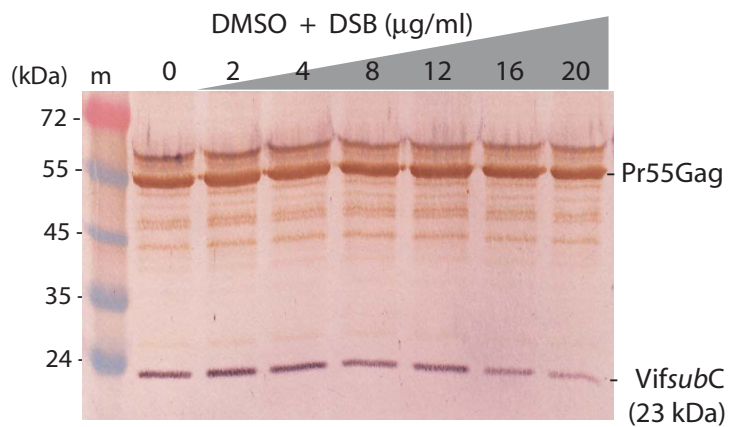

(c) VLP quantification

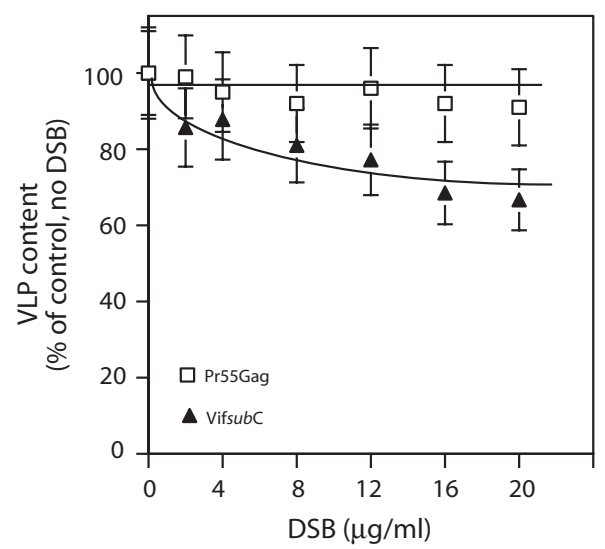

\section{Figure 5}

Counteracting effect of packaging-defective mutant Vif subC on the DSB inhibition of HIV-I VLP assembly. Sf9 cells were coinfected with two baculoviruses at equal MOI of each (5 PFU/cell), one expressing Pr55Gag, the other expressing the double substitution, packaging-defective mutant VifsubC. Cells were treated with increasing concentrations of DSB in DMSO for $30 \mathrm{~h}$ at $18 \mathrm{~h} \mathrm{pi}$, as indicated on top of panels (a) and (b), and on the $x$-axis of panel (c). Cells were harvested at $48 \mathrm{~h}$ $\mathrm{pi}$, and whole cell lysates (WCL) and extracellular VLP analyzed by SDS-PAGE and immunoblotting, using anti-Vif primary antibody and secondary phosphatase-labelled antibody, followed by anti-Gag primary antibody and secondary peroxidase-labelled antibody. (a), WCL; (b), VLP. Note the low level of Vif protein in VLP, consistent with the packaging-defective phenotype of VifsubC [50]. (m), prestained molecular mass markers; (kDa), kiloDaltons. (c), Quantification of Pr55Gag and Vif protein content of VLP, performed by autoradiography of immunoblots with anti-Gag and anti-Vif rabbit antibodies and ${ }^{35} \mathrm{~S}$-labelled secondary anti-rabbit lgG antibody, as described in the legend to Fig. 3 (c). Results were expressed as percentage of control, untreated samples, which was attributed the $100 \%$ value. Mean of three separate experiments \pm standard deviation. 
ubiquitin ligase complex polyubiquitinates APOBEC3G and redirects it to the proteasome $[27,28,58-60]$. Position 116 in HIV-1 Vif belongs to the ZBD domain, and more precisely to the N-terminal portion of loop 2, the large loop defined by the two cysteine residues at positions 114 and $133[26,28]$ (Fig. 4A). It has been recently found that replacement of Ser by Ala at position 116 in Vif did not change the Vif-Cul5 interaction [28]. This result was not totally surprising since position 116 can be occupied by serine, threonine or alanine in HIV-1 and SIV-CPZ strains [61], all residues characterized by short, hydrophilic or hydrophobic, side chains. However, these authors observed that deletion of Ser-116 abolished the Vif-Cul5 interaction, implying that the amino acid residue spacing in loop 2 was critical for Vif functions [28].

Taking the latter observation into account, we substituted the serine residue to a valine at position 116 . We assumed that the bulky side chain of valine would introduce local disorganization in the 3D structure of the ZBD domain, as did the S116 deletion, and would be detrimental to the anti-DSB effect of Vif. We found that the VifS116V mutant was coencapsidated with Gag at the same levels as Vifwt (Fig. 6Bi, lane 0). However, the assembly and extracellular release of VLP from Sf9 cells coexpressing Pr55Gag and VifS116V showed the same degree of DSB susceptibility as the one observed when Pr55Gag was expressed alone (Fig. 6Bi, and Fig. 6C). Thus, the lack of antagonistic effect against DSB of the packageable mutant VifS116V confirmed that anti-DSB function and packaging into VLP were separate functions in the Vif protein.

To further analyze the role of the ZBD structure in the Vif anti-DSB activity, we constructed another mutant of recombinant Vif protein. Cysteine at position 133 in Vif is a residue essential for virus infectivity $[62,63]$, for Zn coordinate formation and ZBD-associated functions in Vif $[27,28]$. We therefore generated mutation C133S in recombinant Vif, and tested mutant VifC133S in coexpression with Pr55Gag in control or DSB-treated Sf9 cells, as above. In untreated cells, VifC133S behaved as VifS116V mutant, and was coencapsidated with Pr55Gag into VLP at levels equivalent to Vifwt (Fig. 6Bii, lane 0). In DSB-treated cell samples, VifC133S had the same phenotype as VifS116V in terms of lack of anti-DSB effect: assembly and release of VLP from Sf9 cells coexpressing Pr55Gag and VifC133S showed the same degree of DSB sensitivity as from Sf9 cells expressing Pr55Gag alone (Fig. 6Bii, and Fig. 6C).

These results suggested that the antagonistic activity of Vif against the DSB inhibition of Gag assembly, absent from VifS116V and VifC133S mutants, was associated with the ZBD and more precisely involved residues located on the $\mathrm{N}$-terminal side of loop 2. Thus, the phenotype of our Vif
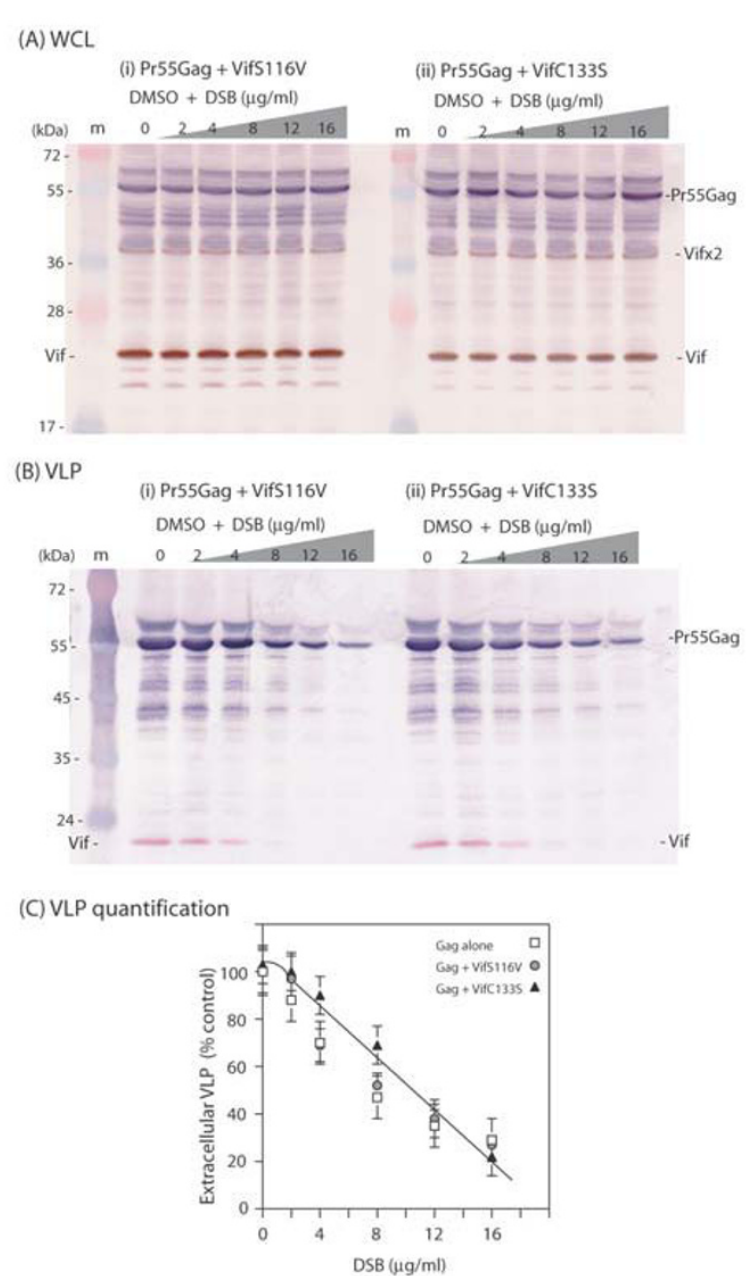

\section{Figure 6}

Absence of anti-DSB effect of zinc-binding domain mutants of Vif. Sf9 cells were coinfected with two baculoviruses at equal $\mathrm{MOI}$ of each (5 PFU/cell), one expressing Pr55Gag, the other expressing VifSII6V (A and B, (i)) or $\mathrm{VifCI} 33 \mathrm{~S}$ (A and B, (ii)). Cells were treated with increasing concentrations of DSB in DMSO for $30 \mathrm{~h}$ at $18 \mathrm{~h}$ pi, as indicated on top of panels (i) and (ii), and on the $x$-axis of panel (C). Cells were harvested at $48 \mathrm{~h} \mathrm{pi}$, and whole cell lysates (WCL) and extracellular VLP analyzed by SDS-PAGE and immunoblotting, using anti-Vif primary antibody and secondary peroxidase-labelled antibody, followed by anti-Gag primary antibody and phosphatase-labelled secondary antibody. (A), WCL; (B), VLP. (m), prestained molecular mass markers; (kDa), kiloDaltons. (C), Quantification of VLP produced by DSB-treated Sf9 cells coexpressing Pr55Gag and Vif mutants was performed using SDS-PAGE and autoradiography of immunoblots reacted with anti-Gag and ${ }^{35}$ S-labelled secondary anti-rabbit IgG antibody, as described in the legends to Fig. 3(c) and 5(c). Results were expressed as percentage of control, untreated samples, which was attributed the $100 \%$ value. Mean of three separate experiments \pm standard deviation. 
mutants with respect to their packaging and anti-DSB properties showed that the integrity of the ZBD structure was not required for the packaging of Vif into VLP produced by Sf9 cells, but was crucial for its DSB counteracting effect.

\section{Assembly and budding pathways of HIV-I VLP in Vif- expressing Sf9 cells}

To further investigate on the mechanism of the DSB counteracting effect of Vif, Sf9 cells coexpressing Pr55Gag and Vifwt or ZBD mutants were analyzed by electron microscopy (EM) and immunoelectron microscopy (immunoEM). Cells were infected with AcMNPV-Pr55Gag and AcMNPV-Vif, untreated or treated with DSB at $10 \mu \mathrm{g} / \mathrm{ml}$ at $18 \mathrm{~h} \mathrm{pi}$, harvested at $48 \mathrm{~h}$ pi and processed for EM or immuno-EM using anti-Vif antibody. In control Sf9 cells expressing Pr55Gag alone, the vast majority of VLP assembled at and budded from the plasma membrane (Fig. 7a), as shown in previous studies $[16,64,65]$. The pattern of VLP assembly and budding was drastically different in Gag+Vifwt-coexpressing cells: VLP were found in abundance in cytoplasmic vesicles (Fig. 7b). Coexpression of Vif ${ }^{w t}$ did not decrease the production of VLP by Pr55Gagexpressing Sf9 cells [24,50], and vesicular VLP egressed into the extracellular medium by exocytosis (Fig. 7c). In immuno-EM, gold grains of anti-Vif antibodies were seen in close association with intravesicular VLP, or along the rim of VLP-containing vesicles (Fig. 7d, e), suggesting that Vif and Pr55Gag proteins colocalized in the same vesicular compartment.

The proportion of VLP following the intravesicular budding and exocytosis pathway compared to the ones using the plasma membrane pathway was estimated under the EM, by counting several hundreds of VLP in subcellular compartments of more than 20 different cells. In control Sf9 cells expressing Pr55Gag alone, less than 5\% VLP were found within the vesicular compartment, whereas in Gag+Vifwt-coexpressing cells, the proportion increased to 30 to $50 \%$, viz. a 5- to 10 -fold increase. Likewise, in cells coexpressing Pr55Gag and Vifwt and treated with DSB, most VLP used the intravesicular budding and exocytic pathway (Fig. 8). Interestingly, many VLP-containing vesicles showed an electron-dense, heterogenous lumen (Fig. 8 ), resembling multivesicular bodies (MVBs) observed in mammalian cells. MVBs belong to the late endosomal subcellular compartment, and have been identified as the preferred budding sites for WT HIV-1 particles in primary human macrophages (reviewed in [66]), as well as in human epithelial and T cells for gag mutants altered in the cluster of basic amino acids of the matrix (MAp17) domain [67].

We next examined cells coexpressing Pr55Gag and ZBD mutants of Vif under the EM, and found that, in the pres- ence of Vif116V and VifC133S, the VLP budding pathway was similar to the one observed in Sf9 cells expressing Pr55Gag alone, i.e. a majority of VLP budding at the plasma membrane and rare intravesicular VLP (less than 10\%; Fig. 9). The EM pattern of VifS116V and VifC133S mutants was consistent with their phenotype, as both mutants failed to negate the inhibitory effect of DSB on VLP assembly. Taken together, our results suggested that, in the presence of Vifwt, the VLP assembly and budding process was redirected to the vesicular compartment, and that the VLP egress via exocytosis represented a salvage pathway through which HIV-1 VLP escaped the negative effect of DSB.

\section{Discussion}

It is generally accepted that DSB inhibits the cleavage of CAp25 into CAp24 and SP1 by the viral PR, due to its interference with the Gag substrate [8]. However, in recombinant Pr55Gag-expressing Sf9 cells, a cellular context devoid of PR and other viral proteins, DSB showed a dose-dependent inhibitory activity on VLP assembly and release [14]. The aim of the present study was to understand this dual inhibitory activity, and explain the apparent discrepancy between the DSB effects observed in mammalian and non-mammalian, insect cells. We first explored the effect of DSB on VLP production in 5BD.1 cells, a mammalian trans-packaging cell line producing VLP devoid of viral genome, as the VLP produced by AcMNPV-Pr55Gag-infected Sf9 cells. We found that DSB had only a moderate inhibitory effect on VLP yields at high DSB doses (Fig. 1), indicating that VLP assembly in 5BD.1 cells was less sensitive to DSB inhibitor, compared to Pr55Gag-expressing Sf9 cells. This suggested that the DSB negative effect on the VLP assembly process might be modulated by factors depending on the cellular or/and viral context.

We therefore investigated on the possible influence of viral components on the pattern of anti-assembly effect of DSB, and in particular the role of viral partners of Pr55Gag within the capsid. Coexpression of recombinant Pr55Gag with EnvGp160 or Vpr did not modify the level of inhibition of VLP assembly by DSB (Fig. 2), whereas coexpression of Vifwt restored the production of VLP in DSB-treated cells to levels found in the absence of the drug (Fig. 3). A panel of recombinant Vif mutants (Fig. 4) were then tested for their anti-DSB activity. We found that the DSB-antagonistic effect of Vif was retained in packaging-defective mutants of Vif (Fig. 5), but abolished by a Cys-to-Ser substitution at position 133 (Fig. 6Bii), a mutation which destroyed the zinc finger-like structure or ZBD. A phenotype similar to that of VifC133S was observed for mutant VifS116V (Fig. 6Bi), which carried a mutation on the N-terminal side of the large loop (loop 2) generated by the four HCCH coordinates with the $\mathrm{Zn}$ atom (Fig. 4A). 

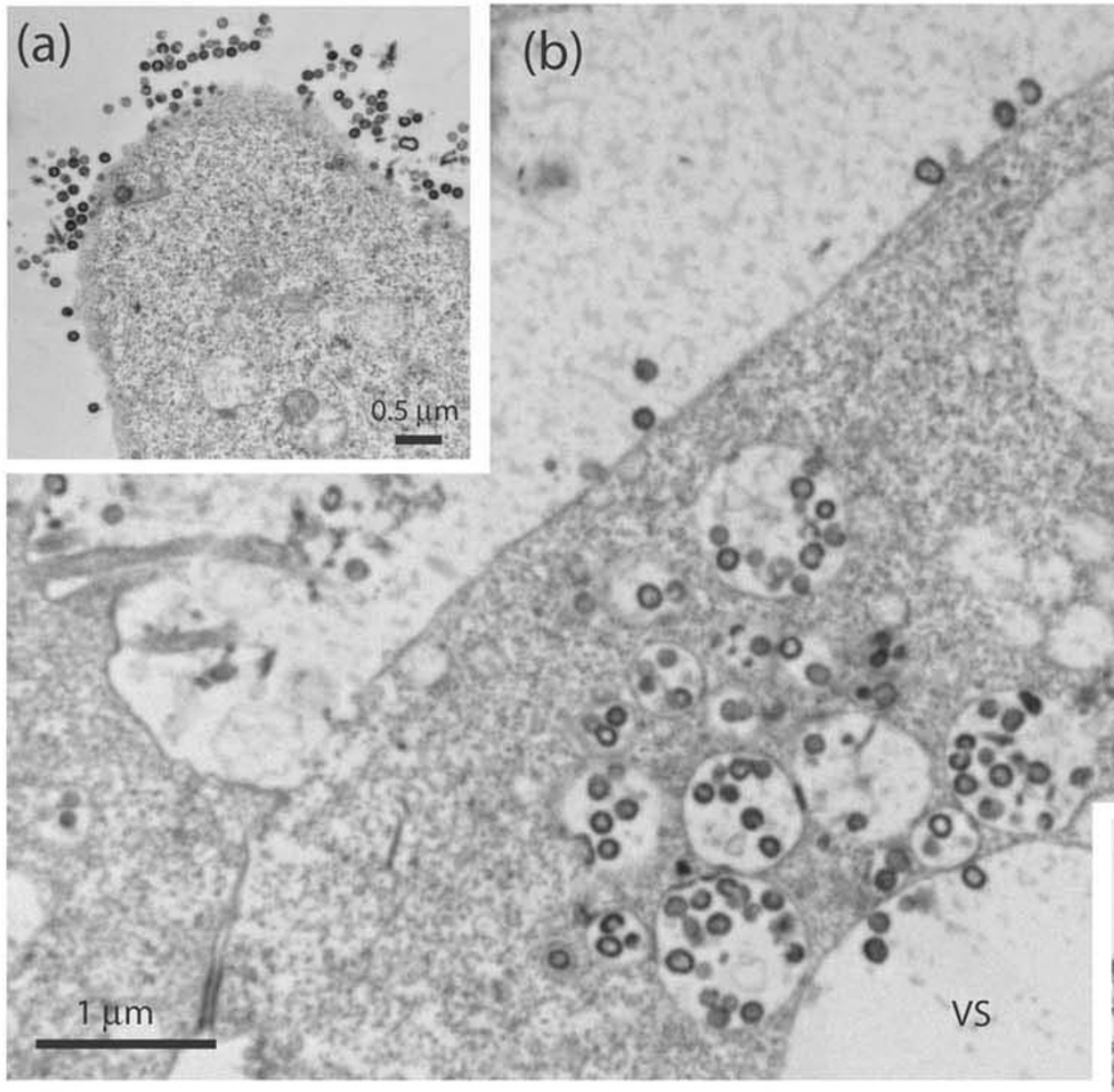

(d)
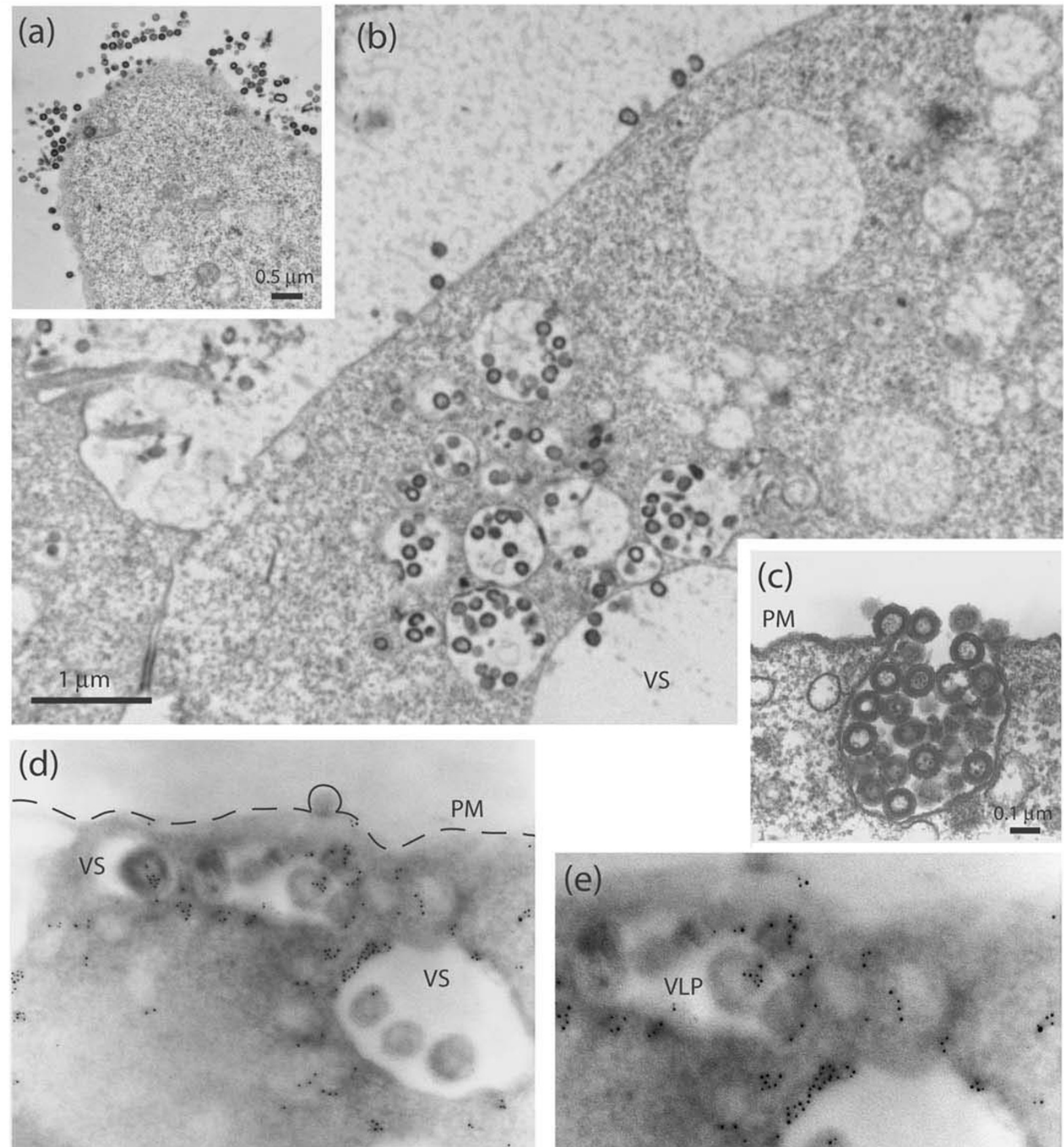

\section{Figure 7}

EM and immuno-EM analysis of Pr55Gag-expressing Sf9 cells, with or without Vifwt coexpression. Sf9 cells were infected with AcMNPV-Pr55Gag alone or coinfected with another baculovirus expressing Vif (AcMNPV-Vifwt) at equal MOI of each (5 PFU/cell), harvested at $48 \mathrm{~h}$ pi, and processed for EM analysis. (a), Control cells expressing Pr55Gag alone; (b), Sf9 coinfected with AcMNPV-Pr55Gag and AcMNPV-Vifwt. Inset (c), Enlargement of an area of the plasma membrane showing exocytosis of VLP. Note the abundance of VLP at the cell surface in (a), compared to the high VLP content of vesicular compartment in (b). (d, e), Sf9 coinfected with AcMNPV-Pr55Gag and AcMNPV-Vifwt and harvested at $48 \mathrm{~h}$ pi were processed for immuno-EM. Cell sections were incubated with anti-Vif rabbit antibody, followed by 5-nm colloidal gold-tagged anti-rabbit lgG antibody. (d), General view of a cell. The plasma membrane (PM) is materialized by a dotted line; the cytoplasmic area shows vesicles (VS) with intraluminal budding of VLP. (e), Enlargement of VLP-containing vesicles. Note the immunogold labelling of VLP, as well as the accumulation of gold grains at the membrane of VLP-containing vesicles. 

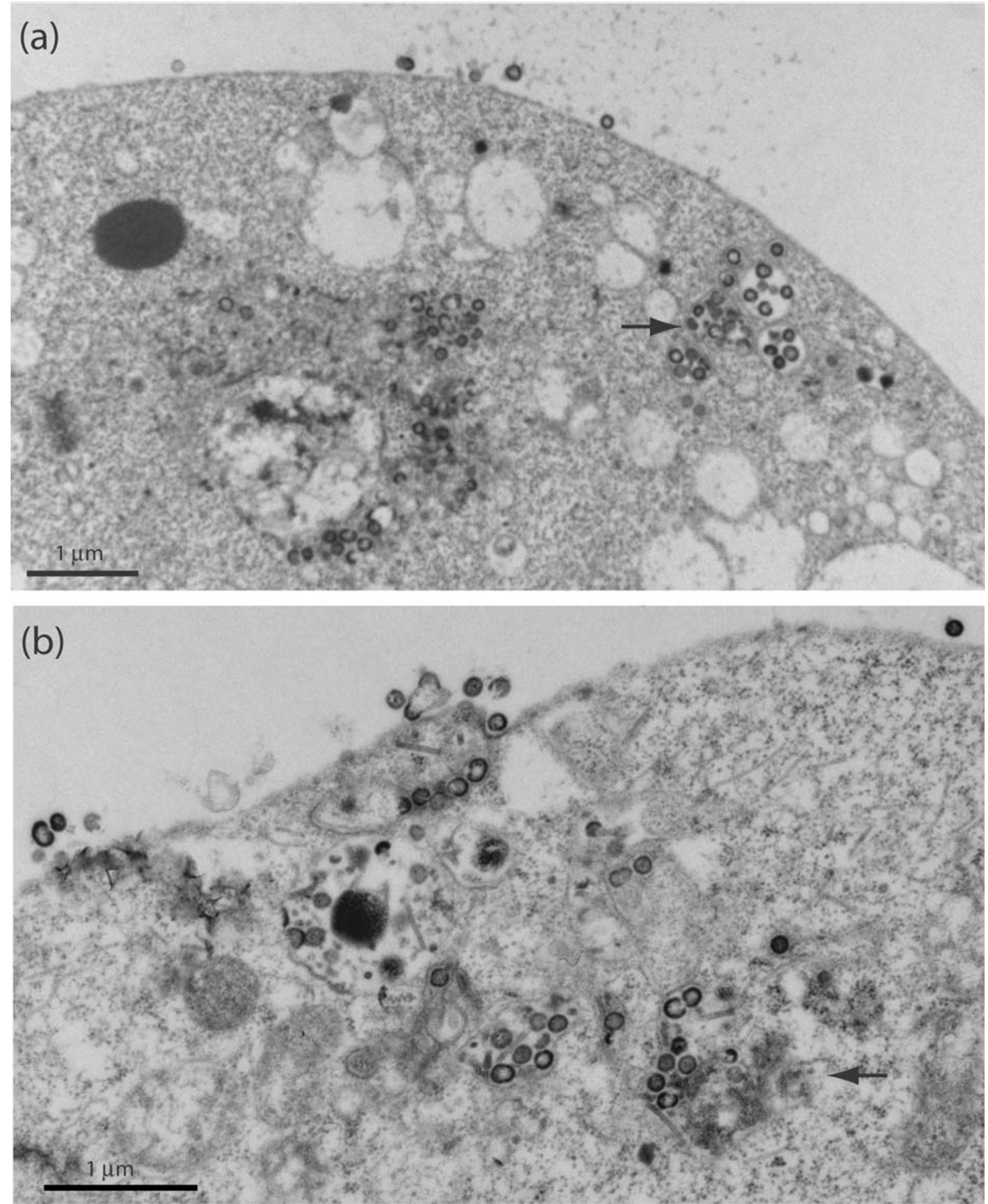

\section{Figure 8}

DSB treatment of Sf9 cells coexpressing Pr55Gag and Vifwt. Sf9 coinfected with AcMNPV-Pr55Gag and AcMNPVVifwtat equal MOI of each (5 PFU/cell) were treated with DSB at $10 \mu \mathrm{g} / \mathrm{ml}$ for $30 \mathrm{~h}$ at $18 \mathrm{~h}$ pi. Cells were harvested at $48 \mathrm{~h}$ pi, and processed for EM. (a), General view of a cell. (b), Enlargement of a submembranal region of the cell showing VLP in the process of exocytosis. Note the abundance of VLP in the vesicular compartment in panels (a) and (b). VLP-containing vesicles reminiscent of MVBs observed in mammalian cells are indicated with arrows. 

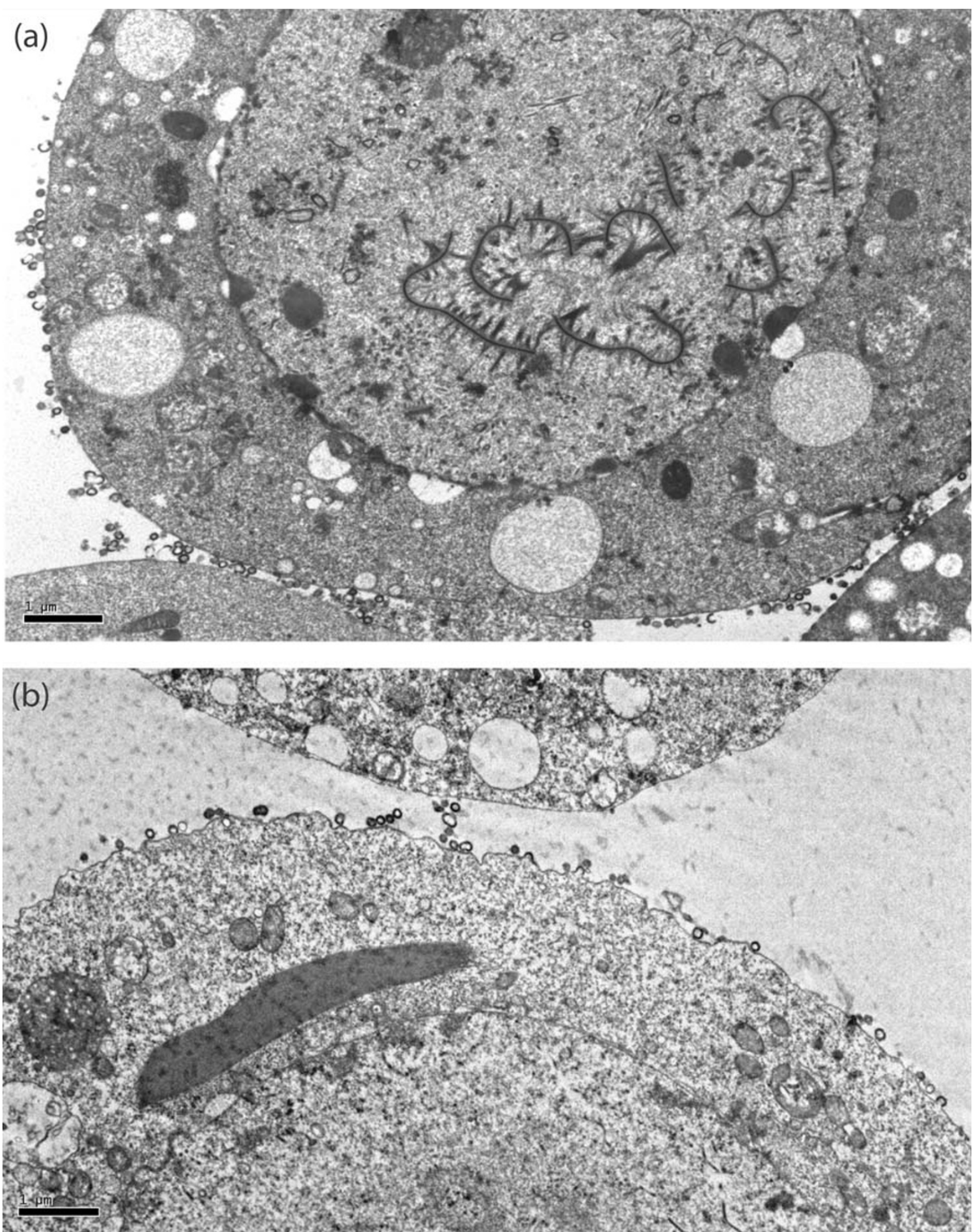

\section{Figure 9}

EM analysis of Sf9 cells coexpressing Pr55Gag and ZBD mutants of Vif. Sf9 were coinfected with AcMNPV-Pr55Gag and AcMNPV-VifSII6V (a) or AcMNPV-VifCI33S (b) at equal MOI of each (5 PFU/cell), harvested at $48 \mathrm{~h}$ pi, and processed for EM analysis. The vast majority of VLP budding at the plasma membrane was reminiscent of Sf9 cells expressing Pr55Gag alone (refer to Fig. 7a), and contrasted with Sf9 cells coexpressing Pr55Gag and Vifwt (refer to Fig. 7b-e). 
Both VifC133S and VifS116V mutants were encapsidated into VLP at levels comparable to Vifwt (Fig. 6Bi and 6Bii, control lanes 0 ). Our results therefore suggested that (i) the anti-DSB effect and packaging into VLP were two independent functions in Vif; (ii) the function of Vif which negated the DSB-induced inhibition of VLP assembly depended on the integrity of the zinc-binding domain, and more precisely on a discrete region of loop 2 overlapping residue 116 (Fig. 4A). This region differed from the Vif packaging signals [50].

EM analysis of Sf9 cells coexpressing Gag and Vifwt or Vif mutants gave some insight into the cellular mechanism of anti-DSB activity of Vif. Sf9 cells coexpressing Pr55Gag and Vifwt, with or without treatment with inhibitory doses of DSB, showed a high proportion of VLP budding into intracytoplasmic vesicles and egressing via exocytosis (Fig. 7b-e and Fig. 8). This contrasted with cells expressing Pr55Gag alone, in which the majority of VLP budded at the plasma membrane (Fig. 7a). When Pr55Gag was coexpressed with one or the other of the ZBD mutants, VifS116V or VifC133S, we observed a drastic change in VLP budding, compared to Vifwt coexpression, consisting of a reversion to the plasma membrane budding pathway, as in Sf9 cells expressing Pr55Gag alone (Fig. 9). Since both ZBD mutants lacked the anti-DSB activity and failed to redirect VLP to the vesicular compartment, as did Vifwt, it might be hypothesized that the antagonistic activity of Vif towards DSB would be the indirect effect of a Vif-mediated change in the VLP assembly sites and mode of cellular exit.

It has been shown that the assembly and release of HIV-1 virions proceeds via two pathways, depending upon the cell type [67]: (i) in primary human macrophages, virions preferentially follow the exosomal pathway via MVBs [6769]; (ii) in HeLa cells and T lymphocytes, the major exgress route consisted of plasma membrane addressing and direct budding at the cell surface, but MA polybasic signal mutants of Gag use the MVB pathway in these cells [67]. Sf9 cells expressing Pr55Gag alone belonged to the second category of cells $[16,64,65]$, but when coexpressed with Vifwt, the VLP assembly and budding process mimicked the MVB budding and exocytic pathway used by MA polybasic mutants in HeLa and T cells. The hypothesis formulated above implied that the intravesicular budding and exocytic pathway of VLP would be less sensitive to DSB inhibitory activity than the plasma membrane assembly and budding pathway usually observed in insect cells. If confirmed, this would be an example of drug resistance mechanism (DSB, in the present case) which involves the bypass of a drug-sensitive assembly and budding pathway by the virus or virus-like particle progeny.

The results of our study suggested that DSB and other betulinic acid derivatives could be considered not only as antivirals for patients treatment in vivo, but also as chemical probes to analyse the molecular and cellular mechanisms of retroviral Gag assembly in vitro. In the latter context, considering Vif as a determinant of the budding pathway usage in Sf9 cells, and as a modulator of the DSB response in terms of VLP assembly, any evaluation of potential HIV-1 assembly inhibitors using the baculovirus-insect cell system should be carried out in the presence of the Vif protein.

\section{Methods}

\section{Chemical synthesis of DSB}

The title compound 3-O-(3',3'-dimethylsuccinyl)-betulinic acid $\left(\mathrm{C}_{36} \mathrm{H}_{56} \mathrm{O}_{6} ; \mathrm{MW}=584.8\right)$ was obtained as originally described [5] with a few minor modifications described in our previous study [14].

\section{Cells}

Simian 5BD.1 packaging cells (obtained from D. Rekosh and M.-L. Hammarskjöld, University of Virginia at Charlottesville) were CMT3-COS-derived cells that stably express HIV-1 Gag-Pol and Env proteins but no Nef $[29,30]$. They were maintained in Iscove's medium supplemented with bovine calf serum (10\%), hygromycin $(200 \mu \mathrm{g} / \mathrm{ml})$, gentamycin $(50 \mu \mathrm{g} / \mathrm{ml})$ and G418 $(1.5 \mathrm{mg} /$ $\mathrm{ml}$ ). Spodoptera frugiperda Sf9 cells were maintained as monolayers, and infected with recombinant baculovirus at a multiplicity of infection (MOI) ranging from 2.5 to 20 $\mathrm{PFU} /$ cell, as previously described $[16,65,70,71]$.

\section{Recombinant baculoviruses}

All the different HIV-1 genes used in the present study, except for $v p r$, were inserted into the genome of Autographa californica MultiCapsid NucleoPolyhedrosis Virus (AcMNPV) under the control of a chimeric AcMNPV-GmNPV polyhedrin promoter [16,65,70]. (i) Gag. AcMNPV-Pr55Gag, expressing the full-length wild type (WT) HIV-1 Gag polyprotein (Pr55Gag), has been described in detail in previous studies $[14,16,65,71]$. (ii) Envelope glycoprotein Gp160. AcMNPV-Gp160 expressed the CCR5-tropic YU2 envelope glycoprotein. (iii) Vpr. The baculovirus clone expressing the oligohistidine-tagged Vpr protein (AcMNPV-Vpr) was obtained from Eric Cohen [72]. (iv) Vif clones (refer to Fig. 4). AcMNPV-Vifwt expressed the full-length wild type Vif protein. VifsubA (EKEWH-to-DINQN substitution) and VifsubB (WRxxxYto-FExxxF substitution) were mutated in two tryptophancontaining motifs, at position 76-80 and 89-94, respectively; the double mutant VifsubC carried both subA and subB mutations; mutant VifKRA8 had 8 basic residues in the C-terminal domain (residues 156-192) replaced by alanine residues. VifsubC $\Delta 170$ carried the VifsubC multiple substitutions and an additional deletion of the $23 \mathrm{C}$ terminal residues of Vif. VifsubA, VifsubB, VifsubC, VifKRA8 and VifsubC $\Delta 170$ have been characterized in previous studies $[49,50]$. Substitutions Ser-to-Val at position 
116 and Cys-to-Ser at position 133 in the Vif sequence were constructed using the conventional PCR-SOE technique. Recombinant Vif mutants VifS116V and VifC133S were generated by recombination with the baculoviral genome. All mutants were verified by DNA sequencing.

\section{Gag assembly assays}

Aliquots of Sf9 cells $\left(10^{6}\right)$ were infected with recombinant AcMNPV at MOI 10. At $18 \mathrm{~h}$ postinfection (pi), increasing quantities of DSB in DMSO were added. To avoid possible interference with DMSO effect, DMSO was kept constant in volume in the different samples. A stock solution of DSB $(10 \mathrm{mg} / \mathrm{ml}$ DMSO) was diluted with DMSO to obtain a range of DSB concentrations from 0.5 to $30 \mu \mathrm{g}$ DSB per $3 \mu \mathrm{l}$-aliquot of DMSO, and each $3 \mu \mathrm{l}$-aliquot was added to $1 \mathrm{ml}$ of culture medium overlaying the cell monolayers. The cells were harvested at $48 \mathrm{~h}$ pi, and extracellular VLP quantitatively assayed in the culture medium.

\section{Isolation of extracellular virus-like particles (VLP)}

Sf9 cell culture supernatants were clarified by low-speed centrifugation, then VLP recovered using sucrose-step gradient centrifugation[73], by pelleting through a cushion of $20 \%$ sucrose in TNE buffer (TNE: $100 \mathrm{mM} \mathrm{NaCl}, 10$ $\mathrm{mM}$ Tris-HCl pH 7.4, $1 \mathrm{mM} \mathrm{Na} \mathrm{N}_{2}$ EDTA). The pellets were gently resuspended in PBS (0.20-0.25 ml), and VLP further purified by isopycnic ultracentrifugation in linear sucrose- $\mathrm{D}_{2} \mathrm{O}$ gradients [50]. Gradients $(10-\mathrm{ml}$ total volume, $30-50 \%, \mathrm{w}: \mathrm{v})$ were generated from a $50 \%$ sucrose solution made in $\mathrm{D}_{2} \mathrm{O}$ buffered to $\mathrm{pH} 7.2$ with $\mathrm{NaOH}$, and a $30 \%$ sucrose solution made in $10 \mathrm{mM}$ Tris- $\mathrm{HCl}, \mathrm{pH}$ $7.2,150 \mathrm{mM} \mathrm{NaCl}, 5.7 \mathrm{mM} \mathrm{Na}_{2}$ EDTA. The gradients were centrifuged for $18 \mathrm{~h}$ at $28 \mathrm{krpm}$ in a Beckman SW41 rotor. Aliquots of $0.5 \mathrm{ml}$ were collected from the top, and proteins analyzed by SDS-PAGE, immunoblot analysis with or without autoradiography.

\section{Gel electrophoresis and membrane transfer}

Polyacrylamide gel electrophoresis of SDS-denatured protein samples (SDS-PAGE), and immunoblotting analysis have been described in detail in previous studies $[70,71,74]$. Briefly, proteins were electrophoresed in SDSdenaturing, 12\%-polyacrylamide gel and electrically transferred to nitrocellulose membrane (Hybond $^{\mathrm{TM}}$-Cextra; GE Healthcare Bio-Sciences). Blots were blocked in $5 \%$ skimmed milk in Tris-buffered saline (TBS) containing $0.05 \%$ Tween-20 (TBS-T), rinsed in TBS-T, then successively incubated with primary rabbit, mouse or goat anti-Gag antibodies, and relevant anti-IgG secondary antibodies, at working dilutions ranging from $1: 5,000$ to 1:40,000. Apparent molecular weights were estimated by comparison with prestained protein markers (PageRuler ${ }^{\mathrm{TM}}$ prestained protein ladder; Fermentas Inc., Hanover, MD).

\section{Antibodies and immunological analysis}

Anti-HIV-1 Gag polyclonal antibody (laboratory-made; [50]) was raised in rabbit by injection of bacteriallyexpressed, GST-fused and affinity-purified C-truncated Gag protein consisting of full-length MA domain and the first seventy-eight residues of the CA domain (Pst I site; gag $_{\text {Lai }}$ sequence). Mouse monoclonal antibody (mAb) anti-CAp24 (Epiclone \#5001) and mAb anti-MAp17 (Epiclone \#5003) were obtained from Cylex Inc. (Columbia, $\mathrm{MD}$ ). MAb 41A9, directed against the Gp41 domain of the EnvGp160, was obtained from Hybridolab (Institut Pasteur, Paris). Mouse anti-Hisx6-tag antibody (Tag-100 antibody) was purchased from Qiagen SA (Courtabæuf, France). Anti-Vif antibody was raised in rabbit by injection of bacterially-expressed His-tagged Vif protein purified by guanidine denaturation and progressive renaturation of insoluble protein inclusion, followed by affinity chromatography on Ni-column (a gift from E. Decroly; [75]). Phosphatase-labelled anti-rabbit, or antimouse IgG conjugates were purchased from Sigma (St Louis, MO), and horseradish peroxidase-labelled conjugates from Sigma (St Louis, MO). For immunological quantification of membrane-transferred Gag and Vif proteins, blots were reacted with secondary ${ }^{35}$ SLR-labelled anti-rabbit or anti-mouse whole IgG antibody (GE Healthcare Bio-Sciences; 2,000 Ci/mmol; 20-30 $\mu \mathrm{Ci}$ per $100 \mathrm{~cm}^{2}$ membrane), and exposed to radiographic films (Hyperfilm $^{\mathrm{TM}} \mathrm{MP}$, GE Healthcare Bio-Sciences). Autoradiograms were scanned and quantitated by densitometric analysis, using the VersaDoc image analyzer and the Quantity One program (BioRad). Alternatively, protein bands were excised from blots and radioactivity measured in a scintillation counter (Beckman LS-6500), as previously described $[14,50]$.

\section{Electron microscopy (EM) and immunoelectron microscopy (immuno-EM)}

Baculovirus-infected Sf9 cells were harvested at $48 \mathrm{~h} \mathrm{pi}$, pelleted, fixed with $2.5 \%$ glutaraldehyde in $0.1 \mathrm{M}$ phosphate buffer, $\mathrm{pH} 7.5$, post-fixed with osmium tetroxide $\left(2 \%\right.$ in $\left.\mathrm{H}_{2} \mathrm{O}\right)$ and treated with $0.5 \%$ tannic acid solution in $\mathrm{H}_{2} \mathrm{O}$. The specimens were dehydrated and embedded in Epon (Epon-812; Fulham, Latham, NY). Ultrathin sections were stained with $2.6 \%$ alkaline lead citrate and $0.5 \%$ uranyl acetate in 50\% ethanol, and post-stained with $0.5 \%$ uranyl acetate solution in $\mathrm{H}_{2} \mathrm{O}$ [64]. For immuno-EM analyses, cell specimens were included in metacrylate resin (Lowicryl K4M). Sections on grids were reacted with polyclonal anti-Vif antibody (diluted at 1:100 in Tris-buffered saline) overnight at $4^{\circ} \mathrm{C}$. Reaction with by $5-\mathrm{nm}$ gold-conjugated anti-rabbit IgG goat antibody (EM-GAR5; British Biocell International, Cardiff, UK) was carried out at room temperature for $1 \mathrm{~h}$, and sec- 
tions post-stained with $0.5 \% 0.5 \%$ uranyl acetate solution in $\mathrm{H}_{2} \mathrm{O}[50,64,74,76]$. Grids were examined under a Jeol JEM-1400 electron microscope, equiped with an ORIUS ${ }^{\mathrm{TM}}$ digitalized camera (Gatan France, 78113-Grandchamp). For statistical EM analyses, a minimum of 30 grid squares containing 10 to 20 cell sections each were examined for counting VLP budding at the cell surface, or for core-like particles assembled intracellularly.

\section{Competing interests}

The authors declare that they have no competing interests.

\section{Authors' contributions}

SDF performed the bench work, and BG and PB performed the EM analyses. PC synthesized the DSB. SSH and $\mathrm{PB}$ conceived the strategies and designed the experiments. SB contributed to data analysis. PB wrote the manuscript. All the authors read and approved the final manuscript.

\section{Acknowledgements}

This work has been supported by the Agence Nationale de Recherche sur le SIDA (ANRS Grant 2005-2006/003 and DendrAde-2007). SDF was the recipient of an ANRS fellowship. We are grateful to Eric Cohen (University of Montréal, Québec) for supplying us with the baculoviral clone expressing His-tagged Vpr, and to David Rekosh and Mari-Lou Hammarskjöld (University of Virginia at Charlottesville) for their gift of 5BD.I packaging cells. We acknowledge with thank Elisabeth Errazuriz (Centre Commun d'Imagerie de Laennec) for her significant contribution to specimen processing and EM studies, and Sylvie Fiorini for her expert technical assistance. The efficient secretarial aid of Cathy Berthet is also gratefully acknowledged.

\section{References}

I. Kanamoto T, Kashiwada Y, Kanbara K, Gotoh K, Yoshimori M, Goto T, Sano K, Nakashima H: Anti-human immunodeficiency virus activity of YK-FH3 I 2 (a betulinic acid derivative), a novel compound blocking viral maturation. Antimicrob Agents Chemother 200I, 45: I 225-I230.

2. Li F, Goila-Gaur R, Salzwedel K, Kilgore NR, Reddick M, Matallana C, Castillo A, Zoumplis D, Martin DE, Orenstein JM, Allaway GP, Freed EO, Wild CT: PA-457: a potent HIV inhibitor that disrupts core condensation by targeting a late step in Gag processing. Proc Natl Acad Sci USA 2003, 100:13555-13560.

3. Li F, Zoumplis D, Matallana C, Kilgore NR, Reddick M, Yunus AS, Adamson CS, Salzwedel K, Martin DE, Allaway GP, Freed EO, Wild CT: Determinants of activity of the HIV-I maturation inhibitor PA-457. Virology 2006, 356:217-224.

4. Zhou J, Chen $\mathrm{CH}$, Aiken $\mathrm{C}$ : The sequence of the CA-SPI junction accounts for the differential sensitivity of HIV-I and SIV to the small molecule maturation inhibitor $3-0-\left\{3^{\prime}, 3^{\prime}-\right.$ dimethylsuccinyl\}-betulinic acid. Retrovirology 2004, I:I5.

5. Kashiwada Y, Hashimoto F, Cosentino LM, Chen CH, Garrett PE, Lee $\mathrm{KH}$ : Betulinic acid and dihydrobetulinic acid derivatives as potent anti-HIV agents. J Med Chem 1996, 39:1016-1017.

6. Zhou J, Yuan X, Dismuke D, Forshey BM, Lundquist C, Lee KH, Aiken $\mathrm{C}$, Chen $\mathrm{CH}$ : Small-molecule inhibition of human immunodeficiency virus type I replication by specific targeting of the final step of virion maturation. J Virol 2004, 78:922-929.

7. Zhou X, Parent LJ, Wills JW, Resh MD: Identification of a membrane-binding domain within the amino-terminal region of human immunodeficiency virus type I Gag protein which interacts with acidic phospholipids. J Virol 1994, 68:2556-2569.

8. Aiken $\mathrm{C}$, $\mathrm{Chen} \mathrm{CH}$ : Betulinic acid derivatives as HIV-I antivirals. Trends Mol Med 2005, I I:3I-36.
9. Pettit S, Moody MD, Wehbie RS, Kaplan AH, Nantermet PV, Klein $C A$, Swanstrom R: The p2 domain of human immunodeficiency virus type I Gag regulates sequential proteolytic processing and is required to produce fully infectious virions. J Virol 1994, 68:8017-8027.

10. Shehu-Xhilaga M, Kräusslich H-G, Pettit S, Swanstrom R, Lee JY, Marshall JA, Crowe SM, Mak J: Proteolytic processing of the p2/ nucleocapsid cleavage site is critical for human immunodeficiency virus type I RNA dimer maturation. J Virol 200I, 75:9156-9164.

II. Adamson CS, Ablan SD, Boeras I, Goila-Gaur R, Soheilian F, Nagashima K, Li F, Salzwedel K, Sakalian M, Wild CT, Freed EO: In vitro resistance to the human immunodeficiency virus type I maturation inhibitor PA-457 (Bevirimat). J Virol 2006, 80:10957-1097I.

12. Sakalian M, McMurtrey CP, Deeg FJ, Maloy CW, Li F, Wild CT, Salzwedel K: 3-O-(3',3'-dimethysuccinyl) betulinic acid inhibits maturation of the human immunodeficiency virus type I Gag precursor assembled in vitro. J Virol 2006, 80:57/6-5722.

13. Zhou J, Huang L, Hachey DL, Chen CH, Aiken C: Inhibition of HIVI maturation via drug association with the viral Gag protein in immature HIV-I particles. I Biol Chem 2005, 280:42। 49-42। 55 .

14. DaFonseca S, Blommaert A, Coric P, Hong SS, Bouaziz S, Boulanger $P$ : The 3-O-(3',3'-dimethylsuccinyl) derivative of betulinic acid (DSB) inhibits the assembly of virus-like particles in HIV-I Gag precursor-expressing cells. Antiviral Ther 2007, I 2(8): I I 85-I 203.

15. Kashiwada Y, Sekiya M, lkeshiro Y, Jujioka T, Kilgore NR, Wild CT, Allaway GP, Lee K-H: 3-O-glutaryl-dihydrobetulin and related monoacyl derivatives as potent anti-HIV agents. Bioorg Med Chem Lett 2004, 14:585I-5853.

16. Royer M, Hong SS, Gay B, Cerutti M, Boulanger P: Expression and extracellular release of human immunodeficiency virus type I Gag precursors by recombinant baculovirus-infected cells. J Virol 1992, 66:3230-3235.

17. Yuan X, Huang L, Ho P, Labranche C, Chen $\mathrm{CH}$ : Conformation of gp 120 determines the sensitivity of HIV-I DHOI 2 to the entry inhibitor IC9564. Virology 2004, 324:525-530.

18. Labrosse B, Pleskoff O, Sol N, Jones C, Henin Y, Alizon M: Resistance to a drug blocking human immunodeficiency virus type I entry (RPR I036 II) is conferred by mutations in gP4I. J Virol 1997, 71:8230-8236.

19. Adamson CS, Freed EO: Human immunodeficiency virus type I assembly, release and maturation. Adv Pharmacol 2007, 55:347-387

20. Accola MA, Höglund S, Göttlinger HG: A putative alpha-helical structure which overlaps the capsid-p2 boundary in the human immunodeficiency virus type I Gag precursor is crucial for viral particle assembly. I Virol 1998, 72:2072-2078.

21. Bachand F, Yao XJ, Hrimech M, Rougeau N, Cohen EA: Incorporation of $\mathrm{Vpr}$ into human immunodeficiency virus type I requires a direct interaction with the $\mathrm{p} 6$ domain of the p55 gag precursor. J Biol Chem 1999, 274:9083-909I.

22. Jenkins Y, Pornillos O, Rich RL, Myszka DG, Sundquist WI, Malim MH: Biochemical analyses of the interactions between human immunodeficiency virus type I Vpr and p6(Gag). J Virol 200 I, 75: 10537-10542.

23. Müller B, Tessmer U, Schubert U, Kräusslich H-G: Human immunodeficiency virus type I Vpr protein is incorporated into the virion in significantly smaller amounts than Gag and is phosphorylated in infected cells. J Virol 2000, 74:9727-973I.

24. Bardy M, Gay B, Pébernard S, Chazal N, Courcoul M, Vigne R, Decroly $E$, Boulanger $P$ : Interaction of human immunodeficiency virus type I Vif with Gag and Gag-Pol precursors: coencapsidation and interference with viral protease-mediated Gag processing. I Gen Virol 200I, 82:2719-2733.

25. Akari H, Fujita M, Kao S, Khan MA, Shehu-Xhilaga M, Adachi A, Strebel K: High level expression of human immunodeficiency virus type-I Vif inhibits viral infectivity by modulating proteolytic processing of the Gag precursor at the p2/nucleocapsid processing site. J Biol Chem 2004, 279: I2355-12362.

26. Lv W, Liu Z, Jin H, Yu X, Zhang L, Zhang L: Three-dimensional structure of HIV-I VIF constructed by comparative modeling and the function characterization analyzed by molecular dynamics simulation. Org Biomol Chem 2007, 5:617-626. 
27. Xiao Z, Ehrlich E, Yu Y, Luo K, Wang T, Tian C, X-F Y: Assembly of HIV-I Vif-Cul5 E3 ubiquitin ligase through a novel zinc-binding domain-stabilized hydrophobic interface in Vif. Virology 2006, 349:290-299.

28. Xiao Z, Xiong Y, Zhang W, Tan L, Ehrlich E, Guo D, Yu X-F: Characterization of a novel Cullin5 binding domain in HIV-I Vif. J Mol Biol 2007, 373:54I-550.

29. Srinivasakumar N, Chazal N, Helga-Maria C, Prasad S, Hammarskjöld $M-L$, Rekosh D: The effect of viral regulatory protein expression on gene delivery by human immunodeficiency virus type I vectors produced in stable packaging cell lines. J Virol 1997, 71:584|-5848.

30. Alexander M, Bor Y-C, Ravichandra KS, Hammarskjö_Id M-L, Rekosh D: Human immunodeficiency virus type I Nef associates with lipid rafts to downmodulate cell surface CD4 and class major histocompatibility complex expression and to increase infectivity. J Virol 2004, 78: I685-1696.

31. Cimarelli A, Darlix J-L: Assembling the human immunodeficiency virus type I. Cell Mol Life Sci 2002, 59: I I 66-I I 84.

32. Freed EO: HIV-I Gag proteins: diverse functions in the virus life cycle. Virology 1998, 25 I:I-I5.

33. Demirov DG, Freed EO: Retrovirus budding. Virus Res 2004, 106:87-102.

34. Freed EO, Martin MA: Domains of the human immunodeficiency virus type I matrix and gp4 I cytoplasmic tail required for envelope incorporation into virions. J Virol 1996, 70:34|-35I

35. Freed EO, Mouland AJ: The cell biology of HIV-I and other retroviruses. Retrovirology 2006, 3:77.

36. Murakami T, Freed EO: Genetic evidence for an interaction between human immunodeficiency virus type I matrix and alpha-helix 2 of the gp4l cytoplasmic tail. J Virol 2000, 74:3548-3554

37. Aiken C, Trono D: Nef stimulates human immunodeficiency virus type I proviral DNA synthesis. J Virol 1995, 69:5048-5056.

38. Forshey BM, Aiken C: Disassembly of human immunodeficiency virus type I cores in vitro reveals association of Nef with the subviral ribonucleoprotein complex. J Virol 2003 77:4409-44|4

39. Welker R, Harris M, Cardel B, Krausslich HG: Virion incorporation of human immunodeficiency virus type I Nef is mediated by a bipartite membrane-targeting signal: analysis of its role in enhancement of viral infectivity. J Virol 1998, 72:8833-8840.

40. Welker R, Kottler H, Kalbitzer HR, Krausslich HG: Human immunodeficiency virus type I Nef protein is incorporated into virus particles and specifically cleaved by the viral proteinase. Virology 1996, 21 9:228-236.

4I. Mahalingam S, Khan SA, Murali R, Jabbar MA, Monken CE, Collman RG, Srinivasan A: Mutagenesis of the putative alpha-helica domain of the Vpr protein of human immunodeficiency virus type I: effect on stability and virion incorporation. Proc Natl Acad Sci USA 1995, 92:3794-3798.

42. Morellet N, Bouaziz S, Petitjean P, Roques BP: NMR structure of the HIV-I regulatory protein Vpr. J Mol Biol 2003, 327:2 I 5-227.

43. Singh SP, Tomkowicz B, Lai D, Cartas M, Mahalingam S, Kalyanaraman VS, Murali R, Srinivasan A: Functional role of residues corresponding to helical domain II (amino acids 35 to 46) of human immunodeficiency virus type I Vpr. J Virol 2000, 74:10650-10657.

44. Yao XJ, Subbramanian RA, Rougeau N, Boisvert F, Bergeron D Cohen EA: Mutagenic analysis of human immunodeficiency virus type I Vpr: role of a predicted $\mathbf{N}$-terminal alpha-helical structure in $\mathrm{Vpr}$ nuclear localization and virion incorporation. J Virol 1995, 69:7032-7044.

45. Accola MA, Bukovsky AA, Jones MS, Göttlinger HG: A conserved dileucine-containing motif in p6(gag) governs the particle association of $\mathrm{Vpx}$ and $\mathrm{Vpr}$ of simian immunodeficiency viruses SIV(mac) and SIV(agm). J Virol I999, 73:9992-9999.

46. Lu YL, Bennett RP, Wills JW, Gorelick R, Ratner L: A leucine triplet repeat sequence $(L X X) 4$ in p6 gag is important for $\mathrm{Vpr}$ incorporation into human immunodeficiency virus type I particles. J Virol 1995, 69:6873-6879.

47. Selig L, Pages J-C, Tanchou V, Prévéral S, Berlioz-Torrent C, Liu LX, Erdtmann L, Darlix J-L, Benarous R, Benichou S. Interaction with the p6 domain of the Gag precursor mediates incorporation into virions of $\mathrm{Vpr}$ and $\mathrm{Vpx}$ proteins from primate lentiviruses. J Virol 1999, 73:592-600.

48. Votteler J, Studtrucker N, Sörgel S, Münch J, Rücker E, Kirchhoff F, Schick B, Henklein P, Fossen T, Bruns K, Sharma A, Wray V, Schubert U: Proline 35 of human immunodeficiency virus type I (HIVI) Vpr regulates the integrity of the $\mathbf{N}$-terminal helix and the incorporation of $\mathrm{Vpr}$ into virus particles and supports the replication of R5-tropic HIV-I in human lymphoid tissue ex vivo. I Virol 2007, 8 I:9572-9576.

49. Bouyac M, Courcoul M, Bertoia G, Baudat Y, Gabuzda D, Blanc D, Chazal N, Boulanger P, Vigne R, Spire B: Human immunodeficiency virus type I Vif protein binds to the Pr55GAG precursor. J Virol 1997, 7 I:9358-9365.

50. Huvent I, Hong SS, Fournier C, Gay B, Tournier J, Carriere C, Courcoul M, Vigne R, Spire B, Boulanger P: Interaction and co-encapsidation of HIV-I Vif and Gag recombinant proteins. J Gen Virol 1998, 79:1069-1081.

5I. Baraz L, Friedler A, Blumenzweig I, Nussinuv O, Chen N, Steinitz M, Gilon C, Kotler M: Human immunodeficiency virus type I Vifderived peptides inhibit the viral protease and arrest virus production. FEBS Letters 1998, 44I:419-426.

52. Borman AM, Quillent C, Charneau P, Dauguet C, Clavel F: Human immunodeficiency virus type I Vif-mutant particles from restrictive cells: role of Vif in correct particle assembly and infectivity. J Virol 1995, 69:2058-2067.

53. Dettenhofer M, Cen S, Carlson BA, Kleiman L, Yu X-F: Association of human immunodeficiency virus type I Vif with RNA and its role in reverse transcription. J Virol 2000, 74:8938-8945.

54. Goncalves J, Shi B, Yang X, Gabuzda D: Biological activity of human immunodeficiency virus type I Vif requires membrane targeting by C-terminal basic domains. J Virol 1995 , 69:7196-7204.

55. Kao S, Khan MA, Miyagi E, Plishka R, Buckler-White A, Strebel K: The human immunodeficiency virus type I Vif protein reduces intracellular expression and inhibits packaging of APOBEC3G (CEMI5), a cellular inhibitor of virus infectivity. | Virol 2003, 77: I I398-I | 407.

56. Karczewski S, Strebel K: Cytoskeleton association and virion incorporation of the human immunodeficiency virus type I vif protein. I Virol 1996, 70:494-507.

57. Liu H, Wu X, Newman M, Shaw GM, Hahn BH, Kappes JC: The Vif protein of human and simian immunodeficiency viruses is packaged into virions and associates with viral core structures. J Virol 1995, 69:7630-7638.

58. Mehle A, Goncalves J, Santa-Marta M, McPike M, Gabuzda D: Phosphorylation of a novel SOCS-box regulates assembly of the HIV-I Vif-Cul5 complex that promotes APOBEC3G degradation. Genes Dev 2004, 1 8:2861-2866.

59. Mehle A, Strack B, Ancuta P, Zhang C, McPike M, Gabuzda D: Vif overcomes the innate antiviral activity of APOBEC3G by promoting its degradation in the ubiquitin-proteasome pathway. J Biol Chem 2004, 279:7792-7798.

60. Mehle A, Wilson H, Zhang C, Brazier AJ, McPike M, Pery E, Gabuzda D: Identification of an APOBEC3G binding site in HIV-I Vif and inhibitors of Vif-APOBEC3G binding. J Virol 2007, 8I:13235-1324|

61. Stephens EB, Singh DK, Pacyniak E, McCormick C: Comparison of Vif sequences from diverse geographical isolates of HIV type I and SIV(cpz) identifies substitutions common to subtype C isolates and extensive variation in a proposed nuclear transport inhibition signal. AIDS Res Hum Retroviruses 200I, I7:169-177.

62. Ma X-Y, Sova P, Chao W, Volsky DJ: Cysteine residues in the Vif protein of human immunodeficiency virus type I are essential for viral infectivity. J Virol 1994, 68: I7I4-I720.

63. Simon JHM, Sheehy AM, Carpenter EA, Fouchier RAM, Malim MH: Mutational analysis of the human immunodeficiency virus type I Vif protein. J Virol 1999, 73:2675-268I.

64. Gay B, Tournier J, Chazal N, Carrière C, Boulanger P: Morphopoietic determinants of HIV-I GAG particles assembled in baculovirus-infected cells. Virology 1998, 247:160-169.

65. Royer M, Cerutti M, Gay B, Hong SS, Devauchelle G, Boulanger P. Functional domains of HIV-I gag-polyprotein expressed in baculovirus-infected cells. Virology 1991, I 84:417-422. 
66. Resh MD: Intracellular trafficking of HIV-I Gag: how Gag interacts with cell membranes and makes viral particles. AIDS Rev 2005, 7:84-91.

67. Ono A, Freed EO: Cell-type-dependent targeting of human immunodeficiency virus type $I$ assembly to the plasma membrane and the multivesicular body. J Virol 2004, 78:I552-I563.

68. Nydegger S, Foti M, Derdowski A, Spearman P, Thali M: HIV-I egress is gated through late endosomal membranes. Traffic 2003, 4:902-910.

69. Sherer NM, Lehmann MJ, Jimenez-Soto LF, Ingmundson A, Horner SM, Cicchetti G, Allen PG, Pypaert M, Cunningham JM, Mothes W: Visualization of retroviral replication in living cells reveals budding into multivesicuar bodies. Traffic 2003, 4:785-80I.

70. Carrière C, Gay B, Chazal N, Morin N, Boulanger P: Sequence requirement for encapsidation of deletion mutants and chimeras of human immunodeficiency virus type I Gag precursor into retrovirus-like particles. J Virol 1995, 69:2366-2377.

71. Chazal N, Carrière C, Gay B, Boulanger P: Phenotypic characterization of insertion mutants of the human immunodeficiency virus type I Gag precursor expressed in recombinant baculovirus-infected cells. J Virol 1994, 68: I I I-I 22.

72. Yao XJ, Rougeau N, Duisit G, Lemay J, Cohen EA: Analysis of HIVI Vpr determinants responsible for cell growth arrest in Saccharomyces cerevisiae. Retrovirology 2004, I:2I.

73. Muriaux D, Mirro J, Harvin D, Rein A: RNA is a structural element in retrovirus particles. Proc Natl Acad Sci USA 200I, 98:5246-525I.

74. Peytavi R, Hong SS, Gay B, Dupuy d'Angeac A, Selig L, Bénichou S, Benarous R, Boulanger P: H-EED, the product of the human homolog of the murine eed gene, binds to the matrix protein of HIV-I. J Biol Chem 1999, 274:1635-1645.

75. Douaisi M, Dussart S, Courcoul M, Bessou G, Lerner EC, Decroly E, Vigne R: The tyrosine kinases Fyn and Hck favor the recruitment of tyrosine-phosphorylated APOBEC3G into vif-defective HIV-I particles. Biochem Biophys Res Commun 2005, 329:917-924.

76. Violot S, Hong SS, Rakotobe D, Petit C, Gay B, Moreau K, Billaud G, Priet S, Sire J, Schwartz O, Mouscadet JF, Boulanger P: The Human Polycomb Group EED Protein Interacts with the Integrase of Human Immunodeficiency Virus Type I. J Virol 2003, 77:12507-12522.

Publish with Bio Med Central and every scientist can read your work free of charge

"BioMed Central will be the most significant development for disseminating the results of biomedical research in our lifetime. "

Sir Paul Nurse, Cancer Research UK

Your research papers will be:

- available free of charge to the entire biomedical community

- peer reviewed and published immediately upon acceptance

- cited in PubMed and archived on PubMed Central

- yours - you keep the copyright 